AperTO - Archivio Istituzionale Open Access dell'Università di Torino

\title{
Experimental investigation of surface-layer parameters in low wind-speed conditions in a suburban area
}

\section{This is the author's manuscript}

Original Citation:

Availability:

This version is available http://hdl.handle.net/2318/150006

since

Published version:

DOI:10.1002/qj.2271

Terms of use:

Open Access

Anyone can freely access the full text of works made available as "Open Access". Works made available under a Creative Commons license can be used according to the terms and conditions of said license. Use of all other works requires consent of the right holder (author or publisher) if not exempted from copyright protection by the applicable law. 


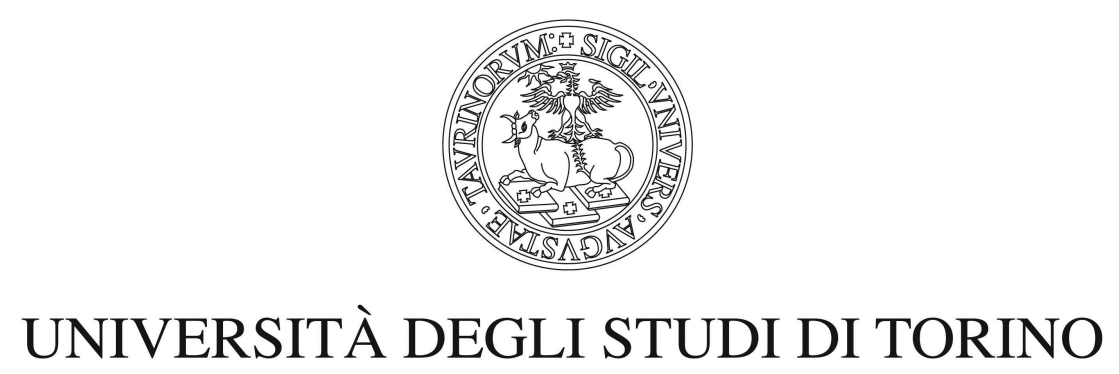

This is an author version of the contribution published on:

S. Trini Castelli, S. Falabino, L. Mortarini, E. Ferrero, R. Richiardone, D. Anfossi

Experimental investigation of surface-layer parameters in low wind-speed conditions in a suburban area.

Quarterly Journal of the Royal Meteorological Society Volume 140, Issue 683 (July 2014 Part B), pages 2023-2036, DOI: $10.1002 /$ qj. 2271 .

The definitive version is available at: http://onlinelibrary.wiley.com/doi/10.1002/qj.2271/abstract 


\section{Experimental investigation of the surface layer parameters in low wind conditions in a suburban area.}

S. Trini Castelli ${ }^{1 *}$, S. Falabino ${ }^{1,3}$, L. Mortarini ${ }^{1}$, E. Ferrero ${ }^{2}$, R. Richiardone ${ }^{3}$, D. Anfossi ${ }^{1}$

${ }^{1}$ Institute of Atmospheric Sciences and Climate, CNR-ISAC, Turin, Italy

${ }^{2}$ Department of Sciences and Advanced Technologies, University of Piemonte Orientale, Alessandria, Italy

${ }^{3}$ Department of Physics, University of Turin, Turin, Italy

*Corresponding author: S.TriniCastelli@isac.cnr.it, ph. +390113839828, fax +390116600364

This article has been accepted for publication and undergone full peer review but has not been through the copyediting, typesetting, pagination and proofreading process, which may lead to differences between this version and the Version of Record. Please cite this article as doi: $10.1002 /$ qj.2271 


\begin{abstract}
.
Low wind conditions in a suburban area were investigated through the analysis of sonic anemometer observations gathered at three vertical levels, $5 \mathrm{~m}, 9 \mathrm{~m}$ and $25 \mathrm{~m}$, during an experimental campaign carried out in the city of Turin in Northern Italy. The data analysis allowed assessing how the surface-layer variables are affected by the specific heterogeneous conditions characterized by calm regime. The applicability of the known theories for the surface layer and their limitations in such environment were investigated. The roughness and the stability parameters, the friction velocity and the wind velocity standard deviations were analyzed accounting for the variability of the wind speed and direction and of the urban structure. Formulations for some of these quantities, to be used in air pollution modelling, were considered, discussed and verified with the observations. The low-wind regime proved to be more effective in influencing the characteristics of the surface layer structure and of the turbulence than the urban geometry itself, this last mainly affecting the surface roughness parameters.
\end{abstract}

Key words: Field campaign, Heterogeneous suburban areas, Low wind, Surface layer, Turbulence 


\section{Introduction}

In this work we are interested in studying the characteristics of the flow and turbulence in low-wind conditions and urban atmosphere, with the final goal of improving the modelling approach when dealing with the dispersion of pollutants in such critical conditions.

The flow and turbulence structure close to the ground and above urban areas can be significantly perturbed by the density and distribution of buildings and other obstacles, together with complex thermal effects and the possible presence of topographical heterogeneities. These particular features affect the dispersion conditions of the atmosphere, where emissions of pollutants from industrial sites, vehicular traffic and domestic heating superpose and interact.

In the devoted literature (e.g. see Fisher et al., 2005 and 2006) the surface layer (SL) in urban areas is divided in two sub-layers, the roughness sublayer (RSL), wherein the flow and turbulence are influenced by individual roughness elements, and the inertial sublayer (ISL), which is the remaining part of the surface layer above the RSL, where the influence of the individual roughness element is mixed up by turbulence. While in the ISL it is expected that the Monin-Obukhov Similarity Theory (MOST hereafter) applies, in general it does not hold in the RSL. It has been already established that the similarity functions based on the MOST are not 'universal' and need to be adapted for heterogeneous conditions (Foken, 2006;

Wilson, 2008). However, they are still largely used in flow and dispersion models even in presence of urban areas. Extensive discussion and evaluation of the MOST for different cases can be found, for instance, in Feigenwinter et al. (1999), Roth (2000), Mahrt (2000), Luhar et al. (2006).

The situation becomes even more complicated in case of calm conditions or low-wind (LW) regime, as for wind speed lower than $1.5 \mathrm{~m} \mathrm{~s}^{-1}$, when it is not generally possible to define a precise mean wind direction. In fact, the more the wind speed decreases, the more the wind 
direction standard deviation increases and the angular sector that can be affected by a point emission can be as large as 360 degrees (Sagendorf and Dickson, 1974). This is due to the occurrence of the wind "meandering", that is to the presence of low frequency (typically 30 60 minutes) horizontal wind oscillations, occurring when the prevailing synoptic wind, near the ground, approaches zero (Anfossi et al., 2005; Öttl et al., 2005). For this reason, lowwind-speed conditions are considered among the most critical conditions to be described and modelled, greatly affecting the effectiveness of the atmospheric dispersion of pollutants. Another crucial aspect when modelling the flow and pollutant dispersion is the scale of interest, since depending on it different parameters can play a primary role. When dealing with the presence of urban environments at the mesoscale, the correspondent roughness and displacement lengths have to characterize the average urban properties. Such parameters can be estimated by examining series of wind data collected on masts, generally located above the roof level, or by the so-called morphometric data, accounting for the density and geometric characteristics of the upwind obstacles. If the local or micro scales are of interest, the values of these lengths need instead to be representative of the near-ground level flow and turbulence (Rooney, 2001), and other classical surface layer parameters characterizing the dispersion, such as the wind velocity standard deviations, have to be referred to. These parameters are generally estimated from wind data collected on masts at the typical height of $10 \mathrm{~m}$ above ground level.

The main goal of this work is to investigate the characteristics of the mean flow and turbulence considering these three aspects, urban features, low-wind speed and scale of interest. The data analysis is a fundamental method to assess the applicability of similarity relationships and surface-layer parameterizations, given that they are generally adopted in the air quality models used for monitoring and regulatory purposes also in such heterogeneous and particular conditions. Here we refer to an observational campaign performed in the city 
of Turin (north-western Italy) in the frame of the Urban Turbulence Project (UTP, Ferrero et al., 2009; Mortarini et al., 2009; Trini Castelli et al., 2011; Mortarini et al., 2012; Trini Castelli et al., 2012; Trini Castelli and Falabino, 2013). Observations were gathered at the UTP site, which constitutes a typical suburban meteorological measuring site and can be considered representative of the general conditions in the entire Po Valley, one of the most polluted regions of Europe, and also of some other European towns, characterised by prevailing low wind (e.g. see Öttl et al., 2001). The availability of the observations at three different levels, $5 \mathrm{~m}, 9 \mathrm{~m}$ and $25 \mathrm{~m}$, allows investigating the vertical structure of the lower part of the urban surface layer.

We present the UTP experiment and the characteristics of the observed dataset in Section 2 and we analyse the effect of the urban structure on the local wind field, in combination with the calm regime, in Section 3. In next Sections we aim at evaluating (i) whether formulations from literature used to estimate roughness layer parameters are still applicable to sparse geometries and low-wind conditions (Section 4); (ii) what are the specific characteristics of the atmospheric stratification in the UTP site and if the Obukhov length can be still reliable for describing them, trying to infer general results that may be of interest for similar conditions (Section 5); (iii) what is the variability of the surface layer and turbulent quantities, starting from the friction velocity (Section 6) towards the wind velocity standard deviations (Section 7), in the context of the UTP site particular conditions, comparing them with parameterizations widely used in literature.

\section{The UTP experiment and the dataset}

The UTP experiment was held in Turin (about 900.000 inhabitants) located at the western edge of the Po Valley at $220 \mathrm{~m}$ a.m.s.l. (above mean sea level). Turin city covers an area of 
about $130 \mathrm{~km}^{2}$ and lies at the foot of a hill range (maximum altitude of about $700 \mathrm{~m}$ a.m.s.1.) on the eastern sector. In the other three sectors it is surrounded by the Alps (whose crest line is about $100 \mathrm{~km}$ distant), including the Apennines in the southern one. The UTP station $\left(45^{\circ} 10^{\prime}\right.$ latitude, $7^{\circ} 38.5^{\prime}$ longitude) is a suburban meteorological station that is located in an area in the southern outskirts of the town on grassy, flat terrain surrounded by buildings and some plots of open field (Figure 1). The distance of tallest buildings (about $30 \mathrm{~m}$ high) from the measuring site is about $150 \mathrm{~m}$ from the north to northeast direction, while in the other directions the closest buildings, characterised by a height ranging from $4 \mathrm{~m}$ to $18 \mathrm{~m}$, are at about $70 \mathrm{~m}$ to $90 \mathrm{~m}$ distance. Therefore, the measurements are taken in a complex and mixed geometry and are not representative of a typical street-canyon configuration or dense urban canopy.

\section{Figure 1}

A ground-based 25-m mast, equipped with horizontal booms pointing West and East at $5 \mathrm{~m}$, $9 \mathrm{~m}, 25 \mathrm{~m}$ height, is located at the centre of the station. Two booms pointing North and South are installed at $25 \mathrm{~m}$ height, too. The three anemometers, recording at $21 \mathrm{~Hz}$, were respectively two Gill Solent 1012R2, placed at $5 \mathrm{~m}$ and $9 \mathrm{~m}$, and a Gill Solent 1012R2A at 25 m. A more detailed description of the equipment is available in Ferrero et al. (2009). The UTP measurement campaign started on 18 January 2007 and ended on 19 March 2008, besides some interruptions for maintenance. The raw data from the three anemometers were synchronized, linearly interpolated to obtain a set with a $20-\mathrm{Hz}$ frequency, processed and stored on a hourly basis. The dataset is composed by a sequence of 10144 hourly-averaged data, corresponding to the full period of the campaign. 
For each anemometer, the hourly-subset data were analysed to detect the Not Available (NA) data, i.e. the missing data due to both the instrument maintenance and the measurement errors. The frequency of NA data in each hour is either very low or very high and NA data series are distributed with continuity, i.e. the wind data are sequences of either good or NA data, but there are no cases of hours with randomly distributed NA data.

The full dataset was then processed applying a linear detrending to remove the low-frequency components of the turbulence spectrum, and a triple rotation (McMillen, 1988; Cassardo et $a l ., 1995)$ that aligns the $\mathrm{x}$-coordinate with the mean streamwise wind direction. Only the hourly averages where at least the $80 \%$ of the data are valid were used in this work, 7833 , 8858 and 8828 hourly series for the 5-m, 9-m and 25-m levels respectively. The dataset was also analysed separating "Day" (3250, 3799 and 3839), "Night" (3277, 3581 and 3510) and "Transition" hours (1306, 1478 and 1479), to take into account the different times of sunrise and sunset during the year and the distinctive features of the transition periods between day and night and viceversa. The "Day" period is defined from one hour after sunrise-time till one hour before sunset-time, "Night" from one hour after sunset till one hour before next sunrise. Two periods determine the "Transition", the first from one hour before to one hour after sunrise, the second from one hour before to one hour after sunset.

Most of the theory of the planetary boundary layer is based on the assumption that the atmosphere is statistically stationary, notwithstanding the atmospheric turbulence is inherently nonstationary. The interest in UTP dataset lies in analysing data that are characterized also by a non-stationary behaviour. In fact, routinely pollution estimation must be performed independently of the stationarity of flow and turbulent parameters. In stable conditions, when turbulence levels are low, data records of one hour may include mesoscale and meandering motion in addition to turbulent motion (Vickers and Mahrt, 2003). The choice of using and analysing one-hour records is driven by the final goal of determining 
wind velocity moments that can be suitable for dispersion calculation. This, also considering that, typically, dispersion models are based on hourly-averaged input data. The one-hour averages can be considered a good compromise for having stationary data and at the same time including the meandering component. In this regard, Luhar (2013) showed that it is necessary to include the meandering motion in the timescales and in the turbulent kinetic energy to correctly describe the dispersion of pollutants in LW conditions.

In order to evaluate the stationarity of the UTP dataset the reverse-arrangement stationarity test suggested in Bendat and Piersol (2000) was applied to all QA-checked one-hour subsets. For each sub-interval the mean, the variance and mean square were evaluated and the test was applied to each of these quantities. Following Bendat and Piersol (2000) we considered as stationary only the hours that satisfy the reverse arrangement for the mean square statistics. The percentages of stationary data are respectively $25 \%$ for the $5-\mathrm{m}$ level, $30 \%$ and $31 \%$ for the 9-m and 25-m levels. In LW conditions and in such complex structures, as urban areas are, observed datasets are likely to be not stationary, due to the nature of the atmospheric processes under observation.

To estimate the confidence intervals of the statistics in LW conditions, we applied the bootstrap resampling procedure (e.g., see Hanna, 1989) to the LW subset of data. The bootstrap analysis was applied at all levels to the $u$-component of the wind velocity standard deviation $\sigma_{u}$, the friction velocity $u_{*}$ and the heat flux $\overline{w^{\prime} \theta^{\prime}}$, calculating the bootstrap bias $B_{b}$ and the bootstrap standard error $\sigma_{b}$ from a population of $m=1000$ resamples.

The bias was found to be very small in all the cases, of the order of $10^{-6}$ for $\sigma_{u}, 10^{-5}$ for $u_{*}$ and $10^{-7}$ for $\overline{w^{\prime} \theta^{\prime}}$ at all levels. The value of $\sigma_{b}$ provides the confidence interval of the bootstrap distribution. A smaller interval indicates a higher significance of the estimated quantities. To evaluate the significance the relative bootstrap standard deviation was 
computed by dividing $\sigma_{b}$ by the median $\widetilde{\psi}$ of the quantity considered (for $\overline{w^{\prime} \theta^{\prime}}$ we considered the median of the absolute values). The ratio $\sigma_{b} / \widetilde{\psi}$, was found to be about $0.1 \%$ for $\sigma_{u}, 1 \%$ for $u_{*}$ and $3-4 \%$ for $\overline{w^{\prime} \theta^{\prime}}$, for all levels. This analysis confirms that the UTP dataset is statistically significant.

\section{Wind Characterization at the UTP site}

The magnitude $\bar{u}$ of the mean wind velocity was calculated from the hourly averaged wind velocity components. Defining as 'low-wind regime' a value of the wind speed lower than $1.5 \mathrm{~m} \mathrm{~s}^{-1}$ (Anfossi et al., 2005; Mortarini et al., 2012), the percentages of LW occurrences, of wind speeds higher than $3 \mathrm{~m} \mathrm{~s}^{-1}$ and the maximum values at the three levels are reported in Table I. It is evident that the prevailing regime at the measuring site is the calm. It is, in fact, well known that the climatology of the Po Valley is characterized by low wind speeds.

\section{Table I}

We analysed the wind roses at all levels. For example, Figure 2 shows the wind rose at the 25 -m height. Here the measurements are the least affected by the closest surrounding urban fabric, composed by low buildings ( $<20 \mathrm{~m}$ height).

The prevailing wind directions recorded at the mast location were mainly from south (S) to south-south-east (SSE) and from north-north-east (NNE). With decreasing measurement height (going from $25 \mathrm{~m}$ to $5 \mathrm{~m}$ ) winds from the NNE become less frequent while the occurrences of winds from SSE and S directions increase. The correspondent wind speeds are relatively low, less than $2 \mathrm{~m} \mathrm{~s}^{-1}$ at $5 \mathrm{~m}$ and $9 \mathrm{~m}$ and less than $3 \mathrm{~m} \mathrm{~s}^{-1}$ at $25 \mathrm{~m}$, and mostly less 
than $1.5 \mathrm{~m} \mathrm{~s}^{-1}$ as above noticed. The strongest speeds, less frequent, are instead associated with winds coming from the north-west sector (from NNW to WNW), as noticeable considering the wind rose at $25 \mathrm{~m}$. They can be related to the flows originating in the Susa valley, which is the main valley surrounding Turin area. We verified that the strongest winds coming from this direction are generally associated with föhn events. The UTP dataset was found to be representative of the climatological means of the area, since the average wind speed at a reference station in Turin city calculated over the period 1990-2004 was found to be $0.8 \mathrm{~m} \mathrm{~s}^{-1}$, the prevailing wind direction in 2007 and 2008 was NNE, the föhn events were 76 in 2007 and 59 in 2008 (ARPA Piemonte, 2008 and 2009)

\section{Figure 2}

To investigate the influence of the surrounding topography and its interaction with the wind, in such dominating calm conditions, the dependence of the wind direction on the height was analysed. The differences $\Delta d i r$ between the wind directions at the three levels were computed per each hour, when observed values were simultaneously available at all three levels (5798 data). The average $\overline{\Delta d i r}$ and the standard deviation $\sigma_{\Delta d i r}$ (Weber, 1992) of the three sets of hourly $\Delta$ dir data were then calculated, for the full dataset and separating day (2376 data), night (2452 data) and transition hours (970 data).

Considering the full dataset the average $\overline{\Delta d i r}$ is negative, from $-2.5^{\circ}$ between $25 \mathrm{~m}$ and $9 \mathrm{~m}$ to $-5.5^{\circ}$ between $25 \mathrm{~m}$ and $5 \mathrm{~m}$. The $\overline{\Delta d i r}$ values in the subsets generally are not large, ranging from $-0.95^{\circ}$ in transition time to a maximum of $-7.1^{\circ}$ in daytime. In a single profile the wind direction difference between $25 \mathrm{~m}$ and $9 \mathrm{~m}$ may happen to have opposite sign with respect to the difference between $9 \mathrm{~m}$ and $5 \mathrm{~m}$. The standard deviations are instead very large, 
ranging from a minimum of $\sigma_{\Delta d i r}=8.3^{\circ}$ between 9 and $5 \mathrm{~m}$ in daytime to $\sigma_{\Delta d i r}=53.5^{\circ}$ between 25 and $5 \mathrm{~m}$ during the night. In fact, in a single wind profile direction differences between different levels are found rising up to $180^{\circ}$, getting large values also in such a short distance as between $9 \mathrm{~m}$ and $5 \mathrm{~m}$. Flow layers may thus happen to be highly decoupled, due both to the low wind speeds and to the buildings structure and trees encountered upwind. However, these effects may act not always in the same way, i.e. they do not cause always the direction difference with the same sign. This is an important issue in relation to the air pollution modelling, since even advanced dispersion models are hardly able to capture such random behaviour, which is not described by the classical boundary-layer parameterizations. The quantities $\overline{\Delta d i r}$ and $\sigma_{\Delta d i r}$ were also calculated as functions of the wind speed, referring to the values at the intermediate height of $9 \mathrm{~m}$. The largest values of $\sigma_{\Delta d i r}$ (from $40^{\circ}$ up to $74^{\circ}$ ) occur generally for lower wind speeds $\left(\bar{u} \leq 0.5 \mathrm{~m} \mathrm{~s}^{-1}\right)$, while both the $\sigma_{\Delta d i r}$ and, to a minor extent, $\overline{\Delta d i r}$ tend to decrease with increasing wind speeds, both reaching their minimum values between all levels for $\bar{u}>3 \mathrm{~m} \mathrm{~s}^{-1}$, from $1.5^{\circ}$ to $2.5^{\circ}$ for $\sigma_{\Delta d i r}$ and from $1.2^{\circ}$ to $-3.5^{\circ}$ for $\overline{\Delta d i r}$.

The variability of the direction due to the interaction between the wind and the topographical features was investigated splitting the area in six sectors characterized by their urbanstructure homogeneity (Figure 1). The observed profiles were appointed to the different sectors referring to the meteorological reference system of incoming wind directions at $9 \mathrm{~m}$ : $350^{\circ}-80^{\circ}$ (1402 data), $80^{\circ}-125^{\circ}$ (240 data), $125^{\circ}-180^{\circ}$ (2282 data), $180^{\circ}-250^{\circ}$ (1265 data), $250^{\circ}-300^{\circ}$ (229 data) and $300^{\circ}-350^{\circ}$ (380 data).

We calculated the distribution of $\overline{\Delta d i r}$ and $\sigma_{\Delta d i r}$ in the different sectors also splitting data in two categories, low wind up to $1.5 \mathrm{~m} \mathrm{~s}^{-1}$, and windy for higher values of wind speeds. For example, Figure 3 shows the boxplots of the differences between the wind directions at $25-\mathrm{m}$ 
and 5-m levels for the two categories, indicating the $\overline{\Delta d i r}$ averaged on the full wind-speed dataset. In all sectors the LW cases show a much larger variation of the wind direction difference with respect to the windy cases. The medians are the same for both LW and windy cases in the sectors with the larger number of data, i.e. the ones characterized by the prevailing wind directions (see also Figure 2). The sectors characterized by a lower number of observed data are those where $\overline{\Delta d i r}$ and $\sigma_{\Delta d i r}$ take higher values, the variability of the direction is larger and the spread between the medians of the two wind-speed categories increases, the wind being probably less channelled.

\section{Figure 3}

Considering all wind speeds together, $\overline{\Delta d i r}$ and $\sigma_{\Delta d i r}$ get the highest values in sectors $80^{\circ}$ $125^{\circ}\left(-27.4^{\circ}\right.$ and $57.8^{\circ}$ between 25 and $\left.5 \mathrm{~m}\right)$ and $250^{\circ}-300^{\circ}\left(15.3^{\circ}\right.$ and $\left.48.9^{\circ}\right)$, whereas lower values are in sectors $350^{\circ}-80^{\circ}, 125^{\circ}-180^{\circ}$ and $180^{\circ}-250^{\circ}$. The minimum values are in the $350^{\circ}-80^{\circ}$ sector for both quantities $\left(-0.3^{\circ}\right.$ and $\left.29.4^{\circ}\right)$. This can be related to the presence of a large extension of tall buildings (about $30 \mathrm{~m}$ ), which act as a screen for the wind. Also, the observations in this sector are taken downwind of the Turin town, thus detecting a flow in equilibrium with the city roughness. Therefore, the flow is less perturbed by the disturbances close to the meteorological tower than in other sectors, and this may contribute to originate such very small values. The $\sigma_{\Delta d i r}$ has always very large values, implying that the flow layers are randomly decoupled.

It was verified that the high values of $\overline{\Delta d i r}$ and $\sigma_{\Delta d i r}$ figures originate in the LW range, while no evident effect on them seems to be related to the building density (Figure 3). Also, when considering all sectors, the average $\overline{\Delta d i r}$ values range from $-2.7^{\circ}$ to $-5.7^{\circ}$ in low wind, 
with $\sigma_{\Delta d i r}$ from $22.7^{\circ}$ to $42.6^{\circ}$, while in windy conditions $\overline{\Delta d i r}$ ranges from $-1.3^{\circ}$ to $-4.6^{\circ}$, with $\sigma_{\Delta d i r}$ from $3.3^{\circ}$ to $5.4^{\circ}$. This aspect, in particular, is supported by the case of sector $80^{\circ}$ $-125^{\circ}$, where $\overline{\Delta d i r}$ and $\sigma_{\Delta d i r}$ get their maxima: here the field is rather open with only a few sheds placed in the vicinity of the mast, therefore showing that the highest values are due to the LW conditions. The results of this analysis lead to an interesting general conclusion, that in low wind speeds the effect of the obstacles on the flow is much less effective than for higher wind speeds.

\section{Estimation and analysis of the roughness parameters}

In this Section we investigate whether (i) the typical methods used in the urban-studies literature to estimate the roughness parameters can be applied in an area dominated by LW conditions and characterized by sparse buildings in the near surrounding; (ii) it is possible to identify characteristic values of the roughness parameters that can be considered representative of the area and used in modelling, considering the variability of the wind directions due to the LW conditions.

To evaluate which among the sonic anemometers were placed into the roughness sublayer, we had to estimate the average height of the buildings $z_{H}$, then we also calculated the displacement $\left(z_{d}\right)$ and the roughness $\left(z_{0}\right)$ lengths.

Two main approaches can be of reference depending on the experimental conditions and on the data available: the morphometric one (Grimmond and Oke, 1999), mostly used when considering the urban area at the mesoscale, and the anemometric - or micrometeorological one (Grimmond et al., 1998), useful for investigating the local and micro scales. 
Morphometric data were only partly available to us, in a limited area of $1.2 \mathrm{~km}$ radius around the measuring site. In the database, the area occupied by the buildings and their locations are specified. The height of the buildings is a general information given as number of storeys, therefore plausible hypotheses were applied to distinguish between civil and industrial buildings placed in the area.

Both morphometric and anemometric methods were applied, for assessing both the mesoscale and local-scale approaches ( Trini Castelli et al., 2012), here we describe the approaches of interest for this study.

\subsection{The morphometric approach}

As a first morphometric approach (MM1 method), we calculated the $z_{H}$ and the plan areal fraction $\lambda_{p}$, needed to estimate $z_{d}$ and $z_{0}$, from the morphometric database, for all wind directions and separately per each of the six sectors (Section 3), thus considering all buildings in the $1.2 \mathrm{~km}$ radius from the mast. The $z_{H}$ was calculated accounting for the different categories of civil buildings and industrial or logistic tanks. The $z_{H}$ and $\lambda_{p}$ values for all

wind directions are reported in Table II. Looking at the values found for the different sectors, given in Table III, we see that the minimum is found in sector $125^{\circ}-180^{\circ}$ and the maximum in sector $350^{\circ}-80^{\circ}$. The numbers are effectively describing the type of geometry locally characterizing the UTP site, that is sparse buildings in the close surrounding and more dense obstacles at farther distances.

Given the $z_{H}$ and $\lambda_{p}$ parameters, the $z_{d}$ and $z_{0}$ lengths were calculated with different formulas used in Grimmond and Oke (1999). In the 'Height-based approach' (called 'Rt'), two simple expressions, $z_{d}=f_{d} z_{H}$ and $z_{0}=f_{0} z_{H}$, where $f_{d}$ and $f_{0}$ are empirical coefficients, are considered. Among the values reported in Grimmond and Oke (1999) we 
chose the coefficients $f_{d}=0.5$ and $f_{0}=0.1$ suggested for urban dispersion

parameterization by Hanna and Chang (1992). Analogous expressions are used in the 'Height and planar areal fraction approaches', including $\lambda_{p}$ parameter: here we used the coefficients $f_{0}=\left(\lambda_{p}\right)^{1.13}, f_{d}=\left(\lambda_{p}\right)^{0.29}$ estimated by Kutzbach (1961), and $f_{0}=\left(1.08 \lambda_{p}-0.08\right), f_{d}=\left(1.4352 \lambda_{p}-0.0463\right)$ estimated by Counihan $(1971)$, named respectively ' $\mathrm{Ku}$ ' and 'Co'.

Considering all wind directions (Table II) a certain variability between the different formulations is found. In the different sectors, for all formulations the minima are found in sector $125^{\circ}-80^{\circ}$, from $z_{0}=0.3 \mathrm{~m}(\mathrm{Ku})$ to $z_{0}=0.5 \mathrm{~m}(\mathrm{Rt})$ while $z_{d}$ sets as $2.3 \mathrm{~m}(\mathrm{Ku})$ and $2.4 \mathrm{~m}(\mathrm{Rt})$. The maxima occur in sector $350^{\circ}-80^{\circ}$ degrees, and change from $z_{0}=0.8 \mathrm{~m}(\mathrm{Rt})$ to $z_{0}=1.6 \mathrm{~m}(\mathrm{Ku})$ and $z_{d}=2.3 \mathrm{~m}(\mathrm{Co})$ to $z_{d}=5.4 \mathrm{~m}(\mathrm{Ku})$. An example of the different values for the sectors is given in Table III for formulation $\mathrm{Ku}$.

The values of the geometrical parameters $\lambda_{p}$ and $z_{H}$ depend on the shape and dimensions of the area where the urban structure is considered to affect the measurements, defined as "source area". To adopt a more rigorous and generalized approach and to investigate the effect that the source area plays on the estimation of the roughness parameters, a second morphometric method, MM2, was applied. In this case we calculated $\lambda_{p}$ and $z_{H}$ following Schmid (1994) for estimating the "source area", represented as an upwind elliptical area with the longitudinal axis parallel to the mean wind direction. The centre of the ellipse is shifted upwind the measurement point of a distance $d$, determined, together with the axes of the ellipse, from Schmid's formulas. These are functions of the non-dimensional surface-layer scaling variables $z / z_{0}, z / L$ and $\sigma_{u, v} / u_{*}$. To determine the source areas, in Schmid's formulas we used as initial values for $z_{0}$ the ones calculated in MM1 from formula Rt. For 
the Obukhov length $L$ (eq. 1 ), the friction velocity $u_{*}$ and the horizontal wind velocity standard deviations $\sigma_{u, v}$ we used the observations at $25 \mathrm{~m}$, since this level is expected to be placed at a height nearby the roughness sub-layer height $z_{*}$, generally defined as about twice the average building height $z_{H}$ (Rotach, 2001). Given the source areas, the computation of $\lambda_{p}$ and $z_{H}$ was performed in each sector for all available hourly data. Then, the medians of the sequence of $\lambda_{p}$ and $z_{H}$ were calculated for all wind directions and separately for the six sectors. We found that in this case the source area extends up to a maximum of $500 \mathrm{~m}$, less than a half of the domain considered in MM1 method.

The $z_{H}$ and $\lambda_{p}$ values for all wind directions are given in Table II. Looking at Table III, we see that the minimum is found in sector $80^{\circ}-125^{\circ}$ and the maximum in sector $350^{\circ}-80^{\circ}$. The $z_{d}$ and $z_{0}$ lengths were then calculated with the same formulas as for MM1 method (see Tables II and III). Through a sensitivity and statistical analysis, it was proven that the final $z_{0}$ values, computed with the different $\mathrm{Rt}, \mathrm{Ku}$ and $\mathrm{Co}$ formulas, are very weakly dependent on the initial $z_{0}$ value and the calculation can therefore be considered reliable.

\section{Table II}

\section{Table III}

It is worth noticing that the estimations of $z_{0}, z_{d}$ and $z_{H}$ were obtained from literature expressions, containing empirical coefficients that are not universal but reflect the characteristics of the site where they were estimated. This may be a limitation in their effective 'transferability' to other sites. We note that the empirical coefficients estimated in Co case generally lead to lower values of the $z_{0}$ and $z_{d}$ with respect to $\mathrm{Ku}$ and Rt. 
Comparing the two morphological methods (Table II) we notice a general decrease of the parameters in MM2 with respect to MM1. This can be mainly related to the different definition of the source area. A confirmation comes from the behaviour of $\lambda_{p}$ and $z_{H}$ as functions of the distance from the measuring point: a strong variability is found in the first $200 \mathrm{~m}$, while after about $900 \mathrm{~m}$ the parameters attain a more constant value. Thus, depending on the area of the urban structure that is considered around the site, different values could be assigned to the roughness parameters. This highlights some difficulty in operating with morphometric data, since in determining the extension of the urban structure that influences a site a certain arbitrariness is unavoidable. The differences are also linked to the fact that while MM1 method is purely morphometric, in MM2 surface-layer parameters are used when determining the extension of the source area, implying that some dynamical features enter its estimation. The specific dynamics of the site, dominated by LW conditions, might therefore contribute, in addition to the smaller dimension of the source area, to reduce the values of the roughness parameters in MM2 method. This suggests that the roughness effect of the urban structure on the flow might be relatively small in the calm regime, and only the area close to the mast strongly influences the flow dynamics under such conditions.

If we consider that the height of the roughness sublayer is twice the average building height, when referring to all wind directions together, then both methods indicate that the two lowest anemometers lay inside the RSL, while the one at $25 \mathrm{~m}$ height is located above the RSL. However, for MM2 method the anemometer at $9 \mathrm{~m}$ is inside the RSL only for sector $350^{\circ}$ $80^{\circ}$, while in the other sector it happens to be above the RSL or just at the boundary between the RSL and the ISL. This is a consequence of the complex heterogeneity of the site and of the fact that there is not a unique and ascertained method to estimate the roughness parameters. 


\subsection{The anemometric approach}

The second approach is 'anemometric' (AM method) and is applied to estimate the roughness layer parameters on the microscale point of view. In fact, when modelling at the microscale, they are the local conditions that govern the pollutant dispersion, and the urban-scale effect of the city is not of interest. Moreover, the anemometric approach could be suitable for the irregular and sparse urban geometry characterizing the UTP site. Grimmond and Oke (1999) already pointed out that wind-based methods have the advantage that, in real cities, “(...) the characteristics of the surface do not need to be specified (the roughness elements can consist of any mix and be arranged in any pattern)". In this case, we considered all three measuring levels and applied the micrometeorological (anemometric) method, based on MOST surface layer concepts, as in Grimmond et al. (1998). This approach is largely used in air quality models to estimate the surface parameters also when performing simulations in urbanized areas.

We selected a subset of the hourly wind velocity profiles ( $45 \%$ of the dataset) that could meet the main MOST constraints, in particular: (i) the values were available at all three levels; (ii) the gradient of the wind speed was positive for growing heights, $\bar{u}_{5 m}<\bar{u}_{9 m}<\bar{u}_{25 m} \mathrm{~m} \mathrm{~s}^{-1}$, to comply with the surface-layer wind profile; (iii) the absolute value of the maximum difference between the wind directions at the subsequent heights was less than 20 degrees, $\Delta \operatorname{dir}_{(25,9),} \Delta \operatorname{dir}_{(9,5)} \leq 20^{\circ}$.

For each selected hourly profile, $z_{d}$ and $z_{0}$ were calculated with a non-linear best fit using the classical surface layer similarity functions (Kaimal and Finnigan, 1994) for the wind speed for the different stability conditions. We investigated the possible dependence of $z_{d}$ and $z_{0}$ on the wind speed, classifying the data with reference to the values at the medium 9$\mathrm{m}$ height, and on the wind direction, considering the six angular sectors used in Section 3. 
The $z_{0}$ shows some variability depending on the wind-speed range and wind direction, ranging from $0.2 \mathrm{~m}$ to $0.7 \mathrm{~m}$ for the different angular sectors. The variability of the displacement length $z_{d}$ is much larger, ranging from a minimum of $0.1 \mathrm{~m}$ to a maximum of $2.9 \mathrm{~m}$, and it clearly depends on the wind speed and on the upwind obstacles. Larger differences are related to the distribution of buildings. In the three sectors ranging from $80^{\circ}$ to $250^{\circ}$, characterized mainly by open fields and some isolated sheds in the close surrounding of the mast, $z_{d}$ attains very small values, approaching zero. The $z_{d}$ values tend to increase when the wind speed increases.

When averaging on all wind directions together, $z_{0}$ changes from $0.3 \mathrm{~m}$ to 0.5 and $z_{d}$ from 0.7 to $2.8 \mathrm{~m}$, getting higher values for increasing wind speeds, in particular when entering the subrange of windy conditions $\bar{u}_{9 m}>3 \mathrm{~m} \mathrm{~s}^{-1}$. These values are in agreement with the ones calculated by MM2 method (see Table II), which determines source areas that are smaller than in MM1 (a maximum of $500 \mathrm{~m}$ radius $v s 1200 \mathrm{~m}$ ) and, as a consequence, more representative of the sparse structures close to the mast. They are also comparable to the lower range found in Grimmond et al. (1998) for low-density classes (Table II in their paper), from 0.46 to $2.04 \mathrm{~m}$ for the roughness length and from 2.46 to $4.5 \mathrm{~m}$ for the displacement length. Following the classification of Britter and Hanna (2003), the UTP category as regards the roughness length at the microscale sets in the rough and very rough category, that is an area moderately covered by low buildings and industrial tanks.

Summarizing: (i) when transferring the typical methods used in the urban-studies literature to estimate the roughness parameters in a heterogeneous and sparse suburban site, the definition of the source area is a key issue and the sensitivity of the resulting parameters with respect to it cannot be neglected; (ii) properly describing the surface roughness parameters at the different scales is important: the relative homogeneity of the surface, spotted by low obstacles 
in the close surrounding of the site, is the dominating effect at the local and micro scales; looking at the site on a larger scale, the effect of the urban structure may be better represented by higher values of the roughness parameters; (iii) in the LW range the roughness parameters tend to take smaller values, indicating that in such conditions the obstacles might modify the flow to a lesser extent. To check this aspect we used also formulas that explicitly account for the drag coefficient and the frontal areal fraction $\lambda_{f}$, as in Grimmond and Oke (1999). We verified that the roughness parameters take plausible values only when the drag coefficient is specifically calculated from the UTP data, therefore accounting for the friction velocity in LW conditions, with respect to use typical values of urban-studies literature. This supports the final statement in Section 3, that in LW conditions the obstacles may be less effective in their interaction with the environmental flow. Such results are not surprising, since the mechanical turbulence develops well when the wind is strong, which is not the case for the UTP site.

In application to air pollution modelling, the variability found may pose some difficulties in choosing proper paired values of $z_{d}$ and $z_{0}$ to be input in the model, since a certain arbitrariness cannot be avoided when fixing a single pair of values, even just for the two classes, low wind and windy.

\section{Analysis of the atmospheric stability}

Considering that in air pollution applications the Obukhov length is often used to determine the stability conditions even when the measurements are taken at heights (typically, $10 \mathrm{~m}$ ) that may be inside the roughness sublayer, here we want to assess (i) whether the $L$ can still effectively describe the atmospheric stratification in a sparse suburban area like the UTP site; 
(ii) what are the limitations of its use in LW conditions, in particular when the surface fluxes are very low.

The $L$ was thus computed at all available levels, as:

$$
L=-\frac{\bar{\theta} u_{*}^{3}}{g k \overline{w^{\prime} \theta^{\prime}}}
$$

being $g$ the gravity acceleration and $k$ the von Karman constant. The mean potential temperature $\bar{\theta}$ and the temperature flux $\overline{w^{\prime} \theta^{\prime}}$ were estimated using the atmospheric sonic temperature measured at each anemometer. Since the anemometer at 25-m height is inside the inertial sublayer, we may consider the $L$ calculated at this level as representative of the stratification conditions, mostly undisturbed by the underlying roughness elements.

We define as neutral the cases where $L$ values correspond to $|L| \geq 500 \mathrm{~m}$, while stable/unstable cases are associated respectively with $0<L<500 \mathrm{~m}$ and $-500<L<0 \mathrm{~m}$.

\subsection{Overall analysis of the stability conditions through the Obukhov length}

In order to assess the reliability of $L$ for estimating the stability in a heterogeneous site like the UTP, we considered also the Richardson number. This depends on mean values and gradients and is less affected by the uncertainties related to calculating the ratio between fluxes, leading to less reliable $L$ when they take very small values. We calculated the Richardson gradient number $R i_{g}=\left(\frac{g}{\bar{\theta}} \frac{\partial \theta}{\partial z}\right) /\left(\frac{\partial \bar{u}}{\partial z}\right)^{2}$ for the two layers between the three vertical levels. Therefore, they are associated with the heights corresponding to the geometrical mean between the two levels, that are $6.7 \mathrm{~m}$ and $15 \mathrm{~m}$, respectively. The $R i_{g}$ was also derived by the Richardson bulk number $R i_{b}=\frac{g}{\bar{\theta}} \frac{z^{2}}{\bar{u}^{2}} \frac{\partial \bar{\theta}}{\partial z}$, since this last is 
considered an useful indicator for stability in low-wind regime, when the wind shear may be too small and $R i_{g}$ becomes "undependable" (Kaimal and Finnigan, 1994). In this case $R i_{g}=\left(R i_{b} / p^{2}\right)$, where for the wind velocity a vertical power law is considered and $p$ is the exponent. We found that the two numbers are in good agreement, therefore both can be used as reference for the stability in UTP LW conditions.

Comparing the stability conditions as identified by $R i_{g}$ and $L$, that is looking at the values of $L$ at $5 \mathrm{~m}$ vs $R i_{g}$ at $6.7 \mathrm{~m}, L$ at $9 \mathrm{~m}$ vs $R i_{g}$ at 6.7 and $15 \mathrm{~m}, L$ at $25 \mathrm{~m}$ vs $R i_{g}$ at $15 \mathrm{~m}$, we found opposite signs in a $30-40 \%$ of the cases, the best agreement being for the $25-\mathrm{m}$ values. Being $R i_{g}$ a 'layer' quantity while the $L$ is estimated at levels, this discrepancy is surely affected by the discontinuous conditions characterizing the vertical distribution in such a complex and built site (see also Section 5.2). However, the main problem, as we will see in Section 5.3, are the very small values of the temperature flux and friction velocities characteristics of the LW conditions. This brings with it a warning about the reliability of the $L$ in heterogeneous conditions and calm regime, even when estimating it in the inertial sublayer.

Since often measurements are available from a single level for modelling applications, preventing the possibility of calculating a Richardson number, we proceeded in analysing the atmospheric stability referring to the $L$ at $25 \mathrm{~m}$ and investigating the differences at the lower levels with respect to it. The frequency of occurrences of the different conditions of the atmospheric stratification resulting from $L$ are reported in Table I for the three levels. We notice (see Table I) that in the subset of unstable cases a not negligible number occur during the "Night hours". These night-time unstable conditions are characterized by a LW regime for about respectively the $97 \%, 95 \%$ and $75 \%$ of the cases at $5 \mathrm{~m}, 9 \mathrm{~m}$ and $25 \mathrm{~m}$.

We analysed the frequency distribution of the stability as a function of the hour of the day, in order to verify whether this kind of occurrences might be due to the range of hours used to split the day and night periods, since, for instance, during Summer time a convective ABL 
may persist for longer than until sunset. A clear polarization of stable cases starting from the late afternoon till the next early morning and of unstable cases in the central hours of the day was appreciated. The neutral cases are related to transition periods or higher wind speeds for about $25 \%$ of their total occurrences.

Differently from what is pointed out in Fisher et al. (2006) on the basis of experimental evidence, that night-time urban conditions remains close to neutral stability, in UTP case the neutral stratification during the night develops only in about $3 \%, 7 \%$ and $9 \%$ of the cases at the 5-m, 9-m and 25-m levels. Stable conditions are the majority during the night, $75 \% \mathrm{~m}$, $71 \%$ and $52 \%$ respectively. This suggests that the mechanical turbulence in the UTP site is not effective enough in mixing the air close to the surface, due to the general LW conditions. The radiative cooling, with the suppression of the thermal turbulence, is the dominating process in determining the stratification in night-time, as already previously found for the Po Valley (Anfossi et al., 1976). Also, considering $z / L$, we can infer that in UTP case the neutral stability in the night cannot be assured, since not only the heat flux is small, but also the friction velocity has small values. Therefore, this last is not effectively dominant and does not force $z / L$ closer to zero. Since the mechanical turbulence in UTP site is generally small, even relatively weak heat fluxes (positive or negative) lead to very stable or unstable conditions. Surely, the low values of $u_{*}$, due to the LW regime, contribute in keeping small the absolute value of $L$, and this has to be kept in mind when analysing these specific conditions.

\subsection{The variability of the stability conditions}

In order to investigate the sensitivity of the stability parameter with respect to the height and its representativeness for the SL structure, we checked when $L$ identifies the same stability at next levels. In the great majority of the cases, the same atmospheric stratification is detected 
at the different levels: $77 \%$ comparing the $L$ at $5 \mathrm{~m}$ and $9 \mathrm{~m}, 67 \%$ both between the $L$ at $5 \mathrm{~m}$ and $25 \mathrm{~m}$, and between $9 \mathrm{~m}$ and $25 \mathrm{~m}$. However, a number of data reveals a stable stratification at one level while the regime detected at the other is unstable: $14 \%$ between $5 \mathrm{~m}$ and $9 \mathrm{~m}, 22 \%$ between $5 \mathrm{~m}$ and $25 \mathrm{~m}, 21 \%$ between $9 \mathrm{~m}$ and $25 \mathrm{~m}$. In the remaining cases a neutral condition at one level corresponds to a non-neutral condition at the other. Considering the $L$ at $25 \mathrm{~m}$ as representative of the actual stability, since the measurements are taken in the inertial sublayer, these percentages help to qualitatively estimate the bias that has to be accounted for when using $L$ as stability parameter in the roughness sublayer.

It is interesting to notice the occurrence of such differences in a small vertical distance such as $4 \mathrm{~m}$, when considering the two lowest levels. They might be linked to a transition phase between different stratification regimes, for instance to the initial development of stable conditions in the late afternoon and to the start of convective conditions in the early hours of the day. We examined the distribution of the hours for the cases when at two next levels different stability conditions are determined. It was clear that these vertical variations occur in large majority in the first hours of the morning and from the late afternoon to the night. Therefore they appear to be connected to the diurnal/nocturnal stability transitions.

\subsection{The stability parameters as a function of the wind regime}

Considering the prevailing LW regime, we analysed the stability through $L$ and the variables $u_{*}, \overline{w^{\prime} \theta^{\prime}}$ as functions of the wind speed: the occurrences of the different stability conditions in the subset of LW cases, $\bar{u}<1.5 \mathrm{~m} \mathrm{~s}^{-1}$, are also reported in Table I. In low wind the percentages of stable and unstable conditions are similar, while a predominance of unstable cases occurs in windy regime, $57 \%$ at $5 \mathrm{~m}, 63 \%$ at $9 \mathrm{~m}$ and $60 \%$ at $25 \mathrm{~m}$. The percentage of 
neutral cases is very small in low wind but higher in windy condition $(17 \%, 24 \%$ and $16 \%$ respectively).

The analysis of the fluxes was performed as a function of the stability and wind speed. This last was found to typify the observations. In Figures 4 and $5 u_{*}$ and $\overline{w^{\prime} \theta^{\prime}}$ are respectively plotted versus the values of the wind speed $\bar{u}$ for the 5-m and 25-m levels, to highlight some important features of these variables. For the windy regime the $u_{*}$ data at $5 \mathrm{~m}$ show two clearly separated distributions (Figure 4) in the different seasons, Spring-Summer (S-S, from April to September) and Autumn-Winter (A-W, from October to March), while this behaviour is not present for LW conditions, where the values are generally more homogeneous and a few higher values distinguish the S-S time from the A-W time. The two straight lines in the graph correspond to the calculated best fit for the values $\bar{u}>1.5 \mathrm{~m} \mathrm{~s}^{-1}$, having slopes $m=0.35$ for the S-S data and $m=0.26$ for the A-W ones. An analogous difference is still present at $9 \mathrm{~m}$ and vanishes when considering the data at $25-\mathrm{m}$ height $(\mathrm{m}=$ 0.17 and 0.18 ), where the seasonal variations in the vegetation, in leaf coverage, and in the terrain, soil and surface characteristics might be less effective.

Plotting the same dataset distinguishing for Day and Night hours, we noticed that the diurnal and nocturnal data are analogously distributed, despite of the different magnitude of the $u_{*}$. This confirms that the previous feature is characteristic of the seasonal cycle.

\section{Figure 4}

On the opposite, the distribution of $\overline{w^{\prime} \theta^{\prime}}$, besides the magnitude of its values, is similar for SS and A-W periods, while it is instead characterized by the diurnal cycle (Figure 5). During the Day hours the unstable conditions dominate both in windy and LW conditions, but in low 
wind the stable conditions occur more frequently than in windy case. Instead, the $\overline{w^{\prime} \theta^{\prime}}$ polarize in a range of very small values, both positive and negative, during Night hours, especially for low wind, while for higher wind speeds the values are generally negative, therefore corresponding to a stable atmospheric stratification. This aspect points out once more the distinguishing characteristics of LW conditions, during which the boundaries between stable and unstable conditions are less sharp than in a typical windy regime, as also reported in Anfossi et al. (2005). This is confirmed also by the $\overline{w^{\prime} \theta^{\prime}}$ data plotted in Figure 5 for the Transition hours (black crosses). They distribute similarly as for the Night hours and they fluctuate in a small range around the zero in low wind, while in windy conditions the $\overline{w^{\prime} \theta^{\prime}}$ values are generally negative, indicating a stable stratification.

Therefore, LW conditions are proven to be much more critical when trying to identify and classify the atmospheric stability when the buoyancy tends to be suppressed.

\section{Figure 5}

The analysis of $u_{*}$ and $\overline{w^{\prime} \theta^{\prime}}$ variables motivated us to investigate the peculiar cases of unstable stratification recorded during Night time. We picked up all cases when during the night a negative $L$ was estimated and we registered their correspondent $u_{*}$ and $\overline{w^{\prime} \theta^{\prime}}$. We verified that in night time $u_{*}$ is small, thus corresponding to LW speeds, and $\overline{w^{\prime} \theta^{\prime}}$ is very small and fluctuates around zero. This occurrence changes $L$ 's sign and produces small values of $L$ originating a 'fake' fluctuation between stable and unstable conditions. This kind of situations is therefore also connected to the difficulty of having a good experimental quality of $\overline{w^{\prime} \theta^{\prime}}$ estimate, which may compromise the reliability of $L$ as proper scale to determine the stability in critical LW conditions. 


\section{Analysis of the friction velocity}

Given the availability of data at three vertical levels, we investigated the values of the friction velocity estimated at different heights. This approach might be useful in urban studies, where the 'local friction velocity', determined as the square root of the local momentum flux, is evaluated at different levels to account for the changing characteristics of the flow and turbulence in complex geometries (Rotach, 1993a and 1993b, Rotach, 1995; Rotach, 2001; Fisher et al., 2006).

For this local approach, we refer to Rotach (1993a) analysis, assessing the vertical variability of $u_{*}$ on observations gathered in an experiment conducted within and above a street canyon, therefore characterizing a fully urban canopy. Rotach (1993a) found that the local friction velocity increases with the height and the stability affects its vertical profile. We investigated whether $u_{*}$ shows a similar variation with the height also in the UTP suburban area and in LW conditions.

First of all, we analysed the hourly series of $u_{*}$ at the three levels, subdividing the dataset in four groups, for which $u_{*}$ regularly increases with the height (G1,45\%), regularly decreases with the height (G2,8\%), increases/decreases between the 5-m and 9-m levels while decreases/increases between the 9-m and 25-m levels (G3, 26\% / G4, 21\%). We evaluated how the hour of the day, the wind speed and direction and the stability characterize the different groups. The G1 data distribute in a relatively homogeneous way for all these variables with a relative peak during the afternoon hours. The G2 occurrences show relative peaks in the morning hours, around 7 a.m., and in the night, around 10 p.m., for stability characterized by $L$ ranging from $-50 \mathrm{~m}$ to $50 \mathrm{~m}$, therefore strongly unstable or stable conditions, for wind directions mainly between $150^{\circ}$ and $200^{\circ}$, where there are low buildings 
close to the mast, and for wind speeds lower than $1.5 \mathrm{~m} \mathrm{~s}^{-1}$ in more than $90 \%$ of the cases. However, the wind speed keeps increasing with the height in more than $95 \%$ of the cases and the difference between the hourly $u_{*}$ at next levels ( 5 and $9 \mathrm{~m}, 9$ and $25 \mathrm{~m}$ ) is largely smaller than $0.05 \mathrm{~m} \mathrm{~s}^{-1}$ in about the $90 \%$ of the cases. This suggests that such few cases of decreasing profiles are linked to fluctuation of $u_{*}$ around small values. An analogous result derives from the analysis of G3 and G4 cases, occurring with a higher relative frequency between $150^{\circ}$ and $200^{\circ}$ and in the early hours of the morning and of the night.

This variable behaviour was then investigated more rigorously. The dataset of the $u_{*}$ vertical profiles, when data are available at all levels (5798 profiles), has been divided in subsets defined by different classes of the hourly averaged wind speed value observed at the 5-m level and other six subsets depending on the wind direction sectors as defined before. In each class, the mean and standard deviation of $u_{*}$ were calculated at the three anemometer levels. We note that considering the class-averaged values, when subdividing dataset in wind speed classes or angular sectors, the profile of the average $u_{*}$ values is always increasing. This confirms that the deviation from a vertically increasing behaviour found analysing the hourly profiles, is due to the fluctuations of the $u_{*}$ around low values, characteristics of LW regimes, which are filtered when averaging.

The analysis of the profiles of the averaged data showed that the difference of the average $u_{*}$ between the two extreme levels of the profiles starts being significant $\left(\bar{u}_{* 25 m}-\bar{u}_{* 5 m}>0.1 \mathrm{~m} \mathrm{~s}^{-}\right.$ ${ }^{1}$ ) for wind speed higher than $1.5 \mathrm{~m} \mathrm{~s}^{-1}$, reaching about $0.5 \mathrm{~m} \mathrm{~s}^{-1}$ for speeds higher than $3 \mathrm{~m} \mathrm{~s}^{-}$ ${ }^{1}$, while in low wind it ranges from $0.01 \mathrm{~m} \mathrm{~s}^{-1}$ to $0.09 \mathrm{~m} \mathrm{~s}^{-1}$. In Table IV we include an estimation of the vertical variability of $u_{*}$ as simple difference and as normalized difference between its class-averaged values at the highest level, $25 \mathrm{~m}$, and the lowest, $5 \mathrm{~m}$, for the six angular sectors. The largest differences are found for the sectors where the highest buildings 
lay, acting as a barrier to the incoming wind. For winds from the $125^{\circ}-180^{\circ}$ sector, where the area close to the mast is almost free of buildings (see Fig. 1), the vertical variation of $u_{*}$ sets around $10 \%$, implying that here all three vertical levels are in the undisturbed surface layer and the MOST could be expected to apply.

\section{Table IV}

Scatter plots of the data processed in wind-speed classes are reported in Figure 6, comparing the pairs at the next vertical levels, $9-\mathrm{m}$ vs $5-\mathrm{m}$ and $25-\mathrm{m}$ vs $9-\mathrm{m}$. The $u_{*}$ is systematically larger at the upper levels, with a larger difference between 5-m and 9-m values (slope of the line $m=1.38)$ than between $9-\mathrm{m}$ and $25-\mathrm{m}(m=1.23)$. The difference between the $u_{*}$ values at the different heights was found to enhance for increasing $u_{*}$. Considering the error bars the observations significantly depart from the perfect-agreement line for high values of $u_{*}(>0.5$ $\mathrm{m} \mathrm{s}^{-1}$ ), that is high values of wind speed.

\section{Figure 6}

The $u_{*}$ profiles have been processed also considering six stability classes as functions of the parameter $z / L$, following Rotach (1993a). The classes have been determined from the value of $z / L$ estimated at $25-\mathrm{m}$ height.

We attempted to draw a parametric formula for $u_{*}$ as a function of the height, and to investigate its dependence on the wind speed regime and stability conditions. We used a simplified formula, inspired by the statistical model of Rotach (1993a), reading as:

$$
u_{*}(z)=C_{1}\left\{1-\exp \left[-C_{2}\left(z-z_{d}\right)\right]\right\}^{C_{3}}
$$


where $C_{1}, C_{2}$ and $C_{3}$ are empirical coefficients.

Having available measurements at three levels, we could determine the coefficients for the UTP site making the $u_{*}$ averaged values satisfy equation (2), at each level for the full dataset. For the displacement length $z_{d}$ here we used the value calculated with MM2 method, formula $\mathrm{Ku}$. Considering the full dataset and including all three levels we obtained the following values for the coefficients: $C_{1}=0.20 \mathrm{~m} \mathrm{~s}^{-1}, C_{2}=0.12 \mathrm{~m}^{-1}$ and $C_{3}=0.26$.

We notice from eq. (2) that $u_{*} \rightarrow C_{1}$ for $z>>z_{d}$, therefore the value of $C_{1}=0.20 \mathrm{~m} \mathrm{~s}^{-1}$ coefficient may be interpreted as the 'undisturbed' value $u_{*_{r}}$ of the friction velocity introduced by Rotach (1993a), defined so that (i) the level ' $r$ ' is least disturbed by the individual roughness elements; (ii) the horizontal inhomogeneity plays a minor role; (iii) the inertial sublayer scaling is valid. The average value of $u_{*}$ at $25 \mathrm{~m}$ is in fact $u_{*}=0.197 \mathrm{~m} \mathrm{~s}^{-1}$. This suggests that at this height the undisturbed level is approached, confirming that the $25-\mathrm{m}$ anemometric level lays inside the inertial sublayer. Also, it follows that equation (2) may be rewritten in the normalized formulation $u_{*} / u_{* r}$ of Rotach (1993a), for UTP case, assigning to his non-dimensional coefficient $C_{l}$ a value of order 1 .

Referring to Table IV, we point out that in UTP case the largest normalized differences of the $u_{*}$ values between the different vertical levels of the profile occur when the stability tends towards neutrality, and to higher wind speeds. The increase of $u_{*}$ with the height is instead smaller in unstable conditions, thanks to the effectiveness of the turbulent mixing. In stable stratification, the increase appears to be larger, but this is due to the small values of $u_{*}$ in the formula. This behaviour is different than what found in Rotach (1993a), where the nearneutral profile showed a less pronounced gradient with respect to stable and unstable conditions. 
In general, it is confirmed that the averaged local friction velocity tend to increase with the height even in such different geometry as the UTP site is. Its gradient is less pronounced at higher levels, which confirms that approaching the 25-m height the RSL merges into the ISL, where the fluxes are expected to be constant. As stated in Rotach (1993a), we can infer that the stability affects the vertical profile of the Reynolds stress and the possible models describing this height dependence need to account for this aspect.

\section{Analysis of the wind velocity standard deviations}

It is well known that the standard deviations of the wind velocity, $\sigma_{i}(i=u, v, w)$, are key variables determining the airborne dispersion. Therefore, there is a large interest in estimating and parameterizing these quantities at all scales, in particular in the urban context (Britter and Hanna, 2003) and in LW conditions (Anfossi et al., 2005; Luhar, 2010). To assess how these turbulent quantities can be parameterized in low wind and heterogeneous conditions as for the UTP site, in the following we analyse their observed values and (i) we draw an analytical function on the basis of best fits applied to the measured data; (ii) we compare the observations and the obtained analytical formulation with parameterizations from literature. The distributions of the observed horizontal components, $\sigma_{u}$ and $\sigma_{v}$, are rather similar and both of them have values less than $0.5 \mathrm{~m} \mathrm{~s}^{-1}$ for about $60 \%$ of the total measurements at the height of $5 \mathrm{~m}$ and $9 \mathrm{~m}$, and about $50 \%$ at $25 \mathrm{~m}$, differently than what found by Hanna (1990), assuming that the hourly-averaged $\sigma_{v}$ maintains a value of about $0.5 \mathrm{~m} \mathrm{~s}^{-1}$ even when wind approaches to zero. The variability of the vertical component $\sigma_{w}$ with the height is larger than for the horizontal components. At the lowest level the measured values are smaller than 
$0.2 \mathrm{~m} \mathrm{~s}^{-1}$ for the $50 \%$, at higher levels the most frequent occurrence sets in between 0.1 and $0.2 \mathrm{~m} \mathrm{~s}^{-1}$.

In the following analysis we adopt a local approach to treat the observed data, given that routine measurements are generally recorded at a single anemometer, so that the interest is investigating the local characteristics at the three levels.

\subsection{Parameterization of the wind velocity standard deviation in low-wind condition}

In order to study the distributions of the $\sigma_{i}$ as functions of the stability conditions, for each level we calculated their local values, normalized over $u_{*}$ and lumped in $z / L$ classes whose width was set equal to 0.2. The class-averaged values are plotted as dots in Figure 7. A nonlinear best fit was applied to the data at the three levels to design a function that can be descriptive of the UTP turbulence observations. The function is a standard formulation and its application also to cases of LW conditions was proposed by the works of Moraes et al. (2005) and Martins et al. (2009):

$$
\frac{\sigma_{i}}{u_{*}}=A_{i}\left\{1+B_{i}\left(\frac{z}{L}\right)\right\}^{C_{i}}
$$

Since for the neutral case it follows that $\frac{\sigma_{i}}{u_{*}}=A_{i}$, to estimate this value we performed an average of the normalized standard deviations over different ranges around the $\frac{z}{L}=0$ value.

The obtained values vary only slightly as functions of these ranges of $z / L$, in particular the vertical value is the same in all the considered cases. For the best-fit procedure we thus assigned to the coefficient $A_{i}$ this average value, which also coincides to the one given in the class $z / L=[-0.01,0.01]$, that is $|L| \geq 500 \mathrm{~m}$ as formerly used for neutral range in this work. 
Then, the other coefficients, $B_{i}$ and $C_{i}$ were left free to vary and were calculated from the best fit on the observed data. To initialize the best fit we refer to the value of $B_{i}$ and $C_{i}$ as given in literature (Roth, 2000; Moraes et al., 2005) . The two free coefficients, $B_{i}$ and $C_{i}$, showed a certain variability depending on the initialization values, in particular for the vertical component. This variability is due to the fact that the observations tend to have a linear behaviour in the strongly stable range and become almost constant at the higher levels (see Figure 7). At the same time, the curves obtained with different pairs of $B_{i}$ and $C_{i}$ values practically superpose. Following the extensive analysis of the empirical coefficients in different experimental cases proposed in Trini Castelli and Falabino (2013), here we fixed the value for $C_{i}$ to 0.33 , and determined $B_{i}$ from the best fit. We verified that estimating the $C_{i}$ directly from the best fit of the observations would bring to negligible differences in the resulting curves. The final coefficients are given in Table V.

\section{Table V}

In Figure 7 the curves calculated through the best fits of the normalized $\sigma_{i}$ are compared to the observed data. To provide a direct comparison, in the figure also the curves calculated with Moraes et al. (2005, 'Moraes et al.' hereafter) coefficients are plotted. In their case the observations refer to very complex terrain, non-urban, characterized by a LW regime.

The UTP values are generally higher than the Moraes et al.'s curve for the horizontal components, while the opposite occurs for the vertical one. This is related to a different redistribution of turbulence in its components, revealing a smaller vertical turbulent transport in the UTP case. The curve produced with Moraes et al.'s coefficient lies in any case inside the variability range of UTP observed data. This seems to indicate that turbulence in LW conditions have common features even in very different sites, as also discussed in Trini 
Castelli and Falabino (2013). Therefore, the function formulated in eq. (3) and the estimated coefficients (Table V) might be exported to other cases where no observations are available for the turbulent variables, which in this way can be estimated from surface layer parameters. Since the differences between UTP and Moraes et al. cases derive from the different values of the empirical coefficients, for possible other applications the set of coefficients that better meet the conditions under study, like urban or not, should be chosen.

\section{Figure 7}

\subsection{A comparison with two parameterizations from the literature}

The goal in this Section is to investigate which are the limitations when applying, in a case like the UTP, parameterizations for the $\sigma_{i}$ that are not specifically derived for low-wind speeds and heterogeneous built environments, and which are therefore based on ISL parameters. We compared our observed data with two turbulence parameterizations from literature, often used in advanced dispersion models, Hanna (1982) and Degrazia et al. (2000).

The Hanna (1982) parameterization ('Hanna' hereafter) provides the turbulence profiles as functions of the surface layer and boundary layer parameters. Different formulations for the variances are proposed, distinguishing the different atmospheric stratification conditions, that is the unstable, stable and neutral cases. In Degrazia et al. (2000; 'Degrazia et al.' hereafter) the expressions for the variances are derived on the basis of Taylor's statistical diffusion theory and of observed spectral properties, so that their profiles are provided as continuous values in the boundary layer at all elevations and all stability conditions. At the different levels, we used the observed local parameters in the formulas of the parameterizations. The 
boundary layer height $h$, used in both parameterizations, has been estimated on the basis of the Batchvarova and Gryning (1991) formulation for the unstable case and following the simple formulas proposed in Zilitinkevich (1972) in the stable and neutral conditions, referring to the ISL parameters at $25 \mathrm{~m}$.

To quantify the comparison between the parameterizations and the observations, we performed a statistical analysis on all available data pairs. In Table VI we report the observed and predicted means and the following metrics for Hanna and Degrazia et al. parameterizations: correlation coefficient (CORR), root mean square error (RMSE), fractional bias (FB) and factor two (FA2).

The metrics confirm that the predictions on average tend to underestimate the observed mean values, and this trend is stronger at higher levels.

\section{Table VI}

The statistics were calculated also separating the three different stratifications, unstable, stable and neutral, to better highlight the performances of the parameterizations depending on the stability. In unstable conditions, the two parameterizations show similar agreements with the observations, CORR is mostly higher than 0.8 , the indices of the error, RMSE and FB, have relatively small values and the FA2 can be considered in general satisfactory, ranging from a minimum of $0.58\left(\sigma_{u}\right.$ at $\left.25 \mathrm{~m}\right)$ up to a maximum of $0.96\left(\sigma_{w}\right.$ at $\left.9 \mathrm{~m}\right)$ for Degrazia $e t$ al. case and $0.70\left(\sigma_{w}\right.$ at $\left.25 \mathrm{~m}\right)$ to $0.93\left(\sigma_{w}\right.$ at $\left.5 \mathrm{~m}\right)$ for Hanna parameterization. In both cases the results for $\sigma_{w}$ are generally better than for the horizontal components. In stable conditions the agreement with the observed data strongly worsens: the observations are always largely underestimated, leading to a rather poor statistics. For instance, the minimum 
and maximum FA2 are found in the same cases with both parameterizations, respectively for $\sigma_{v}$ at $25 \mathrm{~m}$ and $\sigma_{w}$ at $5 \mathrm{~m}$, and correspond to 0.19 and 0.87 for Degrazia et al., 0.07 and 0.85 for Hanna. In the neutral case the statistics are comparable to the unstable case and even a bit better. The correlation is always greater than 0.93 for Hanna, a minimum of 0.77 is found for Degrazia et al. for $\sigma_{v}$ at $25 \mathrm{~m}$; the FA2 gets its lowest value for $\sigma_{v}$ at $25 \mathrm{~m}$ for Degrazia et al. (0.64) and at $5 \mathrm{~m}$ in Hanna case (0.61), for the rest it takes values ranging from 0.82 to 0.99 .

The previous results are confirmed in Figure 8, where the best fit of the normalized observed $\sigma_{i}$ and the corresponding predicted data are plotted as functions of the stability classes.

While the agreement is good in the unstable range, the failure of the parameterization in capturing the distribution of the normalized observed data in stable conditions is evident. This might be related not only to the fact that the parameterizations are designed for flat terrain and not for urban geometries, but it has also to be taken into account that in UTP case the stable conditions are mostly related to LW regime (in $96 \%$ of the cases at $5 \mathrm{~m}$ and $9 \mathrm{~m}$, in $68 \%$ of the cases at $25 \mathrm{~m}$ ), for which the 'classical' formulations should then be modified.

We checked whether the difference of the parameterizations with respect to the observed normalized $\sigma_{i} / u_{*}$ values in stable conditions may be linked to the values of the surface layer parameters and to the formulation themselves. Looking at the distribution of the raw $u_{*}$ data, for increasing $z / L, u_{*}$ tends, as expected, to decrease down to an almost constant value. In the formulation of eq. (3), for increasing $z / L$ and decreasing $u_{*}$ the normalized values $\sigma_{i} / u_{*}$ will therefore tend to increase, as seen in Figures 7 and 8, following the observed data.

The Hanna's formulation for the stable range reads as $\frac{\sigma_{i}}{u_{*}}=a_{i}\left(1-\frac{z}{h}\right)$, where $h$ is the ABL height, $a_{i}=2$ for $i=u$ and $a_{i}=1.3$ for $i=v, w$. It describes a constant value $\left(=a_{i}\right)$ diminished by 
a positive term $\left(=a_{i} z / h\right)$ that at a given height $z$ will tend to increase for stronger stable conditions, since the ABL height $h$ will be smaller. This leads to decreasing $\sigma_{i} / u_{*}$ normalized values. Analogously for Degrazia et al.'s parameterization. Such behaviour can justify the differences seen in Figure 8 for the stable case.

\section{Figure 8}

Summarizing, the Hanna and Degrazia et al. parameterizations are reliable in unstable and neutral conditions, while in the stable case they do not represent the actual turbulence characteristics of the boundary layer in the UTP experiment. Considering that the statistics for the unstable and neutral cases are generally good, we infer that, in UTP case, the LW conditions might be more critical for the correct parameterization of the boundary layer than the urban geometry. The formulation proposed in eq. (3) may therefore be considered as an alternative solution to parameterize the standard deviations of the wind velocity fluctuations. In fact, even when using other empirical coefficients (such as the ones from Moraes et al., 2005) instead of the site specific ones, the curve corresponding to eq. (3) lays inside the variability range (Figure 7). This suggests that this simple formulation may be exported to other cases when the Obukhov length and friction velocity are available.

\section{Summary and conclusions}

In this work the UTP dataset (Ferrero et al., 2009; Trini Castelli et al., 2012), gathered during a 15-months experimental campaign in a suburban site in Turin city (North-West Italy) by three anemometers placed on a mast at heights 5,9 and $25 \mathrm{~m}$, was analysed to investigate the properties of the surface layer parameters in low-wind conditions and in a suburban area. The 
observed data revealed a sharp predominance of the low-wind regime with an average of $89 \%$ wind speed lower than $1.5 \mathrm{~m} \mathrm{~s}^{-1}$ at the first two levels. This aspect, together with the urban complexity of the site, represents the main distinctive characteristics of the dataset. Analysing the morphology of the area, it was found that while the 5-m and 9-m levels set in the roughness sublayer, the observations at $25 \mathrm{~m}$ were gathered in the inertial sublayer, therefore they could be used as reference for assessing the similarity formulations for the UTP site. The data analysis allowed identifying some critical issues that arise when using classical boundary-layer formulations and parameterizations in low wind and heterogeneous conditions. The random vertical variability of the wind direction and the relative decoupling of the flow layers, due mainly to the low wind speeds, cannot be prescribed by standard formulations. The dependence of the roughness parameters on the approach used to estimate them, on the different scales considered and their variability with the wind speed and direction, poses a problem in assigning proper and unique values when modelling the meteorology and dispersion in urbanized areas: it could be therefore recommended to use databases taking into account the diversity of the surface roughness parameters in the studied areas.

Also, in low-wind regime, due to the small and largely fluctuating values of both the friction velocity and the heat flux, the boundaries between stable and unstable conditions are less sharp than in windy regime and using the Obukhov length to describe the stratification might happen to be critical also above the roughness sublayer. In particular, the averaged friction velocity was found not to be constant in the roughness sublayer, thus it follows that its vertical variability has to be taken into account also when modelling a mixed canopy, composed by open fields together with urban structures, often characteristic of suburban areas and typical of the 'neighbourhood scale' (Britter and Hanna, 2003). 
When estimating the wind velocity standard deviations through a best-fit of a stabilitydependent formulation for their normalized values, the curves produced in a different case of low-wind studies (Moraes et al.,2005) were found generally to lie inside the variability range of the UTP observed standard deviations. This implies a possible transferability of the values of the empirical coefficients between similar cases of low-wind conditions. Instead, classical parameterizations for the wind velocity standard deviations, often used in air pollution models, proved to be reliable in neutral and unstable conditions, while largely underestimated their normalized values in stable conditions. The different behaviour of the parameterizations in different stability conditions suggests that low-wind speeds associated to stable stratification may be more critical than the urban complexity in correctly predicting the standard deviations.

As a general result of the wind-regime analysis and of the effect of the buildings on it, we conclude that in a site like the UTP, which could be dynamically categorized as isolatedobstacles flow regime (Grimmond and Oke, 1999), the low-wind regime plays a dominant role in the flow dynamics with respect to the complexity of the geometry. Low-wind conditions are shown to be critical also for the definition of the atmospheric stability, since the boundaries between stable and unstable stratification are less defined than for windy cases. The low-wind regime is found to dominate, with respect to the urban morphology, in determining the characteristics of stratification.

\section{References}

Anfossi D, Bacci P, Longhetto A. 1976. Forecasting of vertical temperature profile in atmosphere during nocturnal radiation inversion from air temperature trend at screen height. Quart. J. Roy. Meteorol. Soc. 102 : $173-180$. 
Anfossi D, Öttl D, Degrazia G, Goulart A. 2005. An analysis of sonic anemometer observations in low wind speed conditions. Boundary-Layer Meteorol. 114 : 179 - 203

ARPA Piemonte, 2008. Rapporto sullo stato dell'Ambiente in Piemonte 2008, published online http://www.arpa.piemonte.it/reporting/rapporto-sullo-stato-dellambiente-in-piemonte, ISBN 88-7479-104-0, $336 \mathrm{pp}$ (in Italian).

ARPA Piemonte, 2009. Rapporto sullo stato dell'Ambiente in Piemonte 2009, published online http://www.arpa.piemonte.it/reporting/rapporto-sullo-stato-dellambiente-in-piemonte, ISBN 88-7479-116-3, $344 \mathrm{pp}$ (in Italian).

Batchvarova E, Gryning SE. 1991. Applied model for the growth of the daytime mixed layer. Boundary-Layer Meteorol. $56: 261-27$.

Bendat JS, Piersol AG. 2000. Random Data: Analysis \& Measurement Procedures. Wiley-Interscience Publishers, 3rd edition, 594 pp

Britter RE, Hanna SR. 2003. Flow and dispersion in urban areas. Annual Review of Fluid Mechanics. 35 : 469 496.

Cassardo C, Sacchetti D, Morselli M G, Anfossi D, Brusasca G, Longhetto A. 1995. A Study of the Assessment of Air Temperature, and Sensible and Latent Heat Fluxes from Sonic Anemometer Observations. Nuovo Cimento. 18C : $419-440$.

Counihan J, 1971. Wind tunnel determination of the roughness lengths as a function of fetch and density of thee-dimensional roughness elements. Atmos Environ. 5 : 637 - 642.

Degrazia G, Anfossi D, Carvalho J, Mangia C, Tirabassi T, Campos Velho H. 2000. Turbulence parameterisation for PBL dispersion models in all stability conditions. Atmos Environ. 34 : 3575 - 3583.

Feigenwinter C, Vogt R, Parlow E. 1999. Vertical Structure of Selected Turbulence characteristics above an Urban Canopy. Theor Appl Climatol. 62 : 51 - 63.

Ferrero E, Anfossi D, Richiardone R, Trini Castelli S, Mortarini L, Carretto E, Muraro M, Bande S, Bertoni D. 2009. 'Urban Turbulence Project - The Field Experimental Campaign'. Internal Report ISAC-TO/02-2009, 37 pp., October 2009, Torino, Italy (available upon request)

Fisher B, Joffre S, Kukkonen J, Piringer M, Rotach M, Schatzmann M, Eds. 2005. Meteorology applied to urban air pollution problems. Final Report COST Action 715. Demetra LtD Publishers, Bulgaria. ISBN 9549526-30-5, $275 \mathrm{pp}$.

This article is protected by copyright. All rights reserved. 
Fisher B, Kukkonen J, Piringer M, Rotach M, Schatzmann M. 2006. Meteorology applied to urban air pollution problems: concepts from COST 715. Atmos Chem Phys. 6 : 555 - 564.

Foken T. 2006. 50 years of the Monin-Obukhov similarity theory. Boundary-Layer Meteorol. 119 : 431 - 447.

Grimmond CSB, King TS, Roth M, Oke TR. 1998. Aerodynamic Roughness of Urban Areas Derived from Wind Observations. Boundary-Layer Meteorol. $89: 1$ - 24

Grimmond CSB, Oke TR. 1999. Aerodynamic properties of urban areas derived from analysis of surface form. $J$ Appl Meteorol. 38 : 1262 - 1292.

Hanna SR. 1982. 'Applications in air pollution modelling'. In: Atmospheric Turbulence and Air Pollution Modelling, Nieuwstadt, F. and Van Dop H. Eds, Reidel, Dordrecht, pp 275-310.

Hanna SR. 1989. Confidence limits for air quality models, as estimated by bootstrap and jacknnife resampling methods. Atmos Environ. 23 : 1385 - 1395.

Hanna SR. 1990. Lateral Dispersion in Light-Wind Stable Conditions. Nuovo Cimento. 13 : 889 - 894.

Hanna SR, Chang JC. 1992. Boundary layer parameterisations for applied dispersion modelling over urban areas. Boundary-Layer Meteorol. 58 : 229 - 259.

Kaimal JC, Finnigan JJ. 1994 Atmospheric Boundary Layer Flows: Their Structure and Measurement. Oxford University Press, 289 pp

Kutzbach J, 1961. Investigations of the modifications of wind profiles by artificially controlled surface roughness. M.S. thesis, Department of Meteorology, University of Wisconsin - Madison, 58 pp.

Luhar AK, Venkatram A, Lee SM. 2006. On relationships between urban and rural near-surface meteorology for diffusion applications. Atmos Environ. $40: 6541-6553$.

Luhar AK. 2010. Estimating Variances of Horizontal Wind fluctuations in Stable Conditions. Boundary-Layer Meteorol. $135: 301-311$.

Luhar, A. K. (2012) Lagrangian Particle Modeling of Dispersion in Light Winds, in Lagrangian Modeling of the Atmosphere, J. Lin, D. Brunner, C. Gerbig, A. Stohl, A. Luhar and P. Webley Eds., American Geophysical Union, Washington, D. C., doi: 10.1029/2012GM001264.

Mahrt L. 2000. Surface heterogeneity and vertical structure of the Boundary Layer. Boundary-Layer Meteorol. $96: 33-62$.

Martins CA, Moraes OLL, Acevedo OC, Degrazia GA. 2009. Turbulence Intensity Parameters over a Very Complex Terrain. Boundary-Layer Meteorol. 133 : 35 - 45.

This article is protected by copyright. All rights reserved. 
McMillen R. 1988. An eddy correlation technique with extended applicability to non-simple terrain. BoundaryLayer Meteorol. $43: 231-245$.

Moraes OLL, Acevedo OC, Degrazia GA, Anfossi D, Da Silva R, Anabor V. 2005. Surface layer turbulence parameters over a complex terrain. Atmos Environ. $39: 3103$ - 3112.

Mortarini L, Ferrero E, Richiardone R, Falabino S, Anfossi D, Trini Castelli S, Carretto E. 2009. Assessment of dispersion parameterizations through wind data measured by three sonic anemometers in a urban canopy. Advances in Science and Research. 3 : 91 - 98.

Mortarini, L., Ferrero, E., Falabino, S., Trini Castelli, S., Richiardone, R. and Anfossi, D. 2013. Low-frequency processes and turbulence structure in a perturbed boundary layer. Quart J Roy Meteorol Soc, 139: 10591072

Öttl D, Almbauer, RA, Sturm, PJ. 2001. A new method to estimate diffusion in stable, low wind conditions. J. Appl. Meteor. $40: 259$ - 268.

Öttl D, Goulart A, Degrazia G, Anfossi D. 2005. A new hypothesis on meandering atmospheric flows in low wind speed conditions. Atmos Environ. 39 : 1739 - 1748.

Rooney GG. 2001. Comparison of upwind land use and roughness length measured in the urban boundary layer. Boundary-Layer Meteorol . $100: 469$ - 486.

Rotach MW. 1993a. Turbulence Close to a Rough Urban Surface Part I: Reynolds Stress. Boundary-Layer Meteorol. $65: 1-28$.

Rotach MW. 1993b. Turbulence Close to a Rough Urban Surface Part II: Variances and Gradients. BoundaryLayer Meteorol. $66: 75-92$.

Rotach MW. 1995. Profiles of turbulence statistics in and above an urban street canyon. Atmos Environ. 29 : $1473-1486$.

Rotach MW. 2001. Simulation of urban-scale dispersion using a Lagrangian stochastic dispersion model. Boundary-Layer Meteorol . 99 : 379 - 410.

Roth M . 2000. Review of Atmospheric Turbulence over Cities. Quart J Roy Meteorol Soc. 126 : 1941 - 1990. Sagendorf JF, Dickson CR. 1974. 'Diffusion under low wind speed, inversion conditions'. NOAA Technical Memorandum ERL, ARL-52, United States of America, 89 pp

Schmid, HP. 1994. Source areas for scalars and scalar fluxes. Boundary-Layer Meteorol. 67 : 293 - 318.

Trini Castelli S, Falabino S, Mortarini L, Ferrero E, Anfossi D, Richiardone R. 2011. Analysis of urban boundary-layer turbulence on the basis of an experimental campaign in Turin city - UTP project. In

This article is protected by copyright. All rights reserved. 
Proceedings of the 14th International Conference on Harmonisation within Atmospheric Dispersion

Modelling for Regulatory Purposes, Kos, Greece, 2-6 October 201, 414-417.

Trini Castelli S and Falabino S. 2013. Parameterization of the wind velocity fluctuation standard deviations in the surface layer in low-wind conditions. Meteorol Atmos Phys. 119, 91-107.

Trini Castelli S, Falabino S, Mortarini L, Ferrero E, Richiardone R, Anfossi D. 2012. Urban Turbulence Project. Analysis of the observed data. Internal report ISAC-TO/03-2012, October 2012, Torino, Italy, 50 pp.

Vickers D and Mahrt L. 2003. The cospectral gap and turbulent flux calculations. J. Atm. Oc. Tech., 20 : 660672.

Weber R. 1992. A comparison of different estimators for the standard deviation of wind direction based on persistence. Atmos Environ. 26A : 983-986.

Wilson JD. 2008. Monin-Obukhov Functions for Standard Deviations of Velocity. Boundary-Layer Meteorol. $129: 353-369$.

Zilitinkevich SS. 1972. On the determination of the height of the Ekman boundary layer. Boundary-Layer Meteorol. 3 : $141-145$.

This article is protected by copyright. All rights reserved. 


\section{Figure captions}

Figure 1. Picture (from Google Maps) of the area surrounding the experimental site (indicated with a cross).. The six angular sectors used as reference in the text are marked on the meteorological reference system (circle).

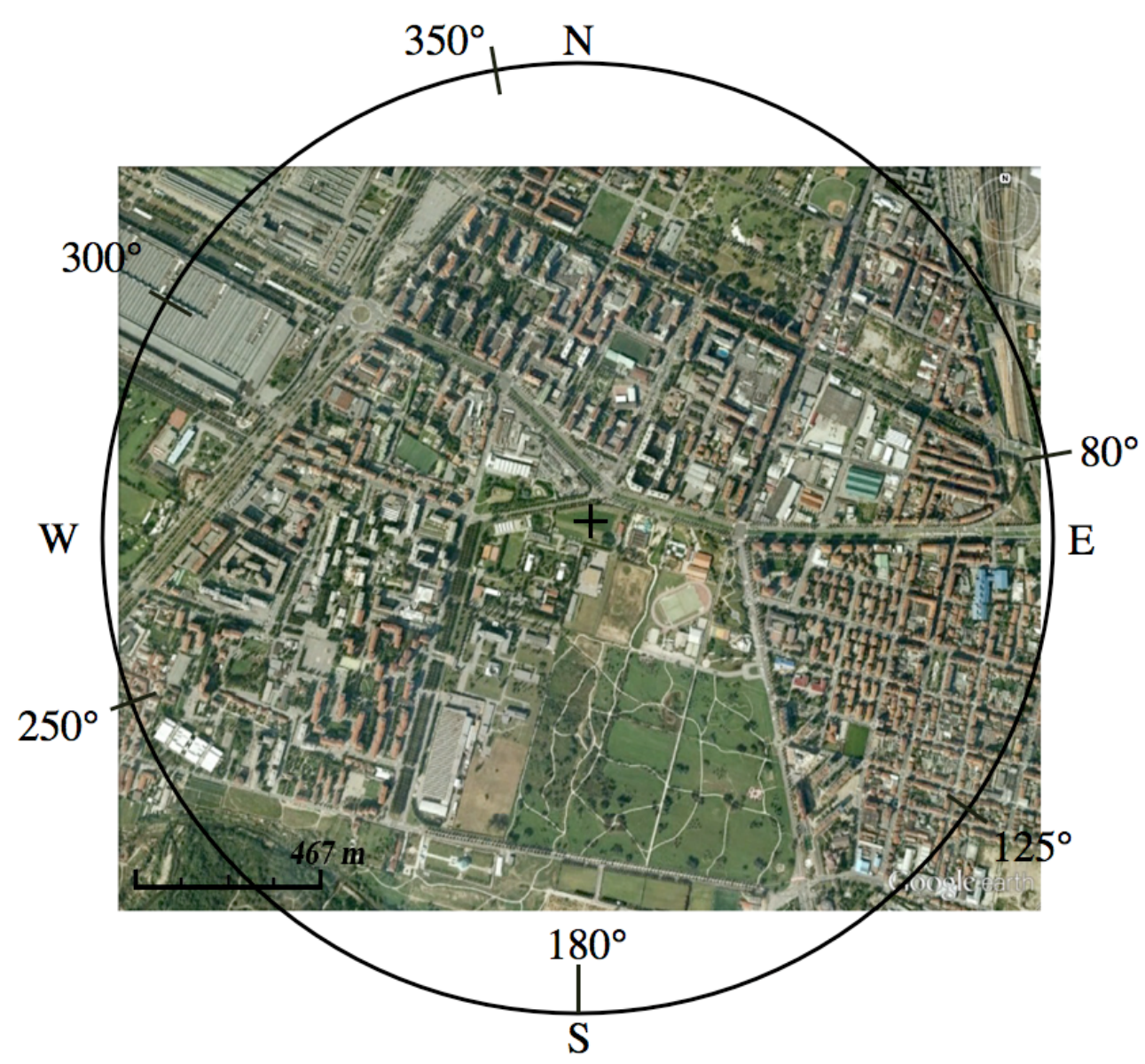

This article is protected by copyright. All rights reserved. 
Figure 2. Wind rose as observed during the UTP campaign period at the 25-m level.
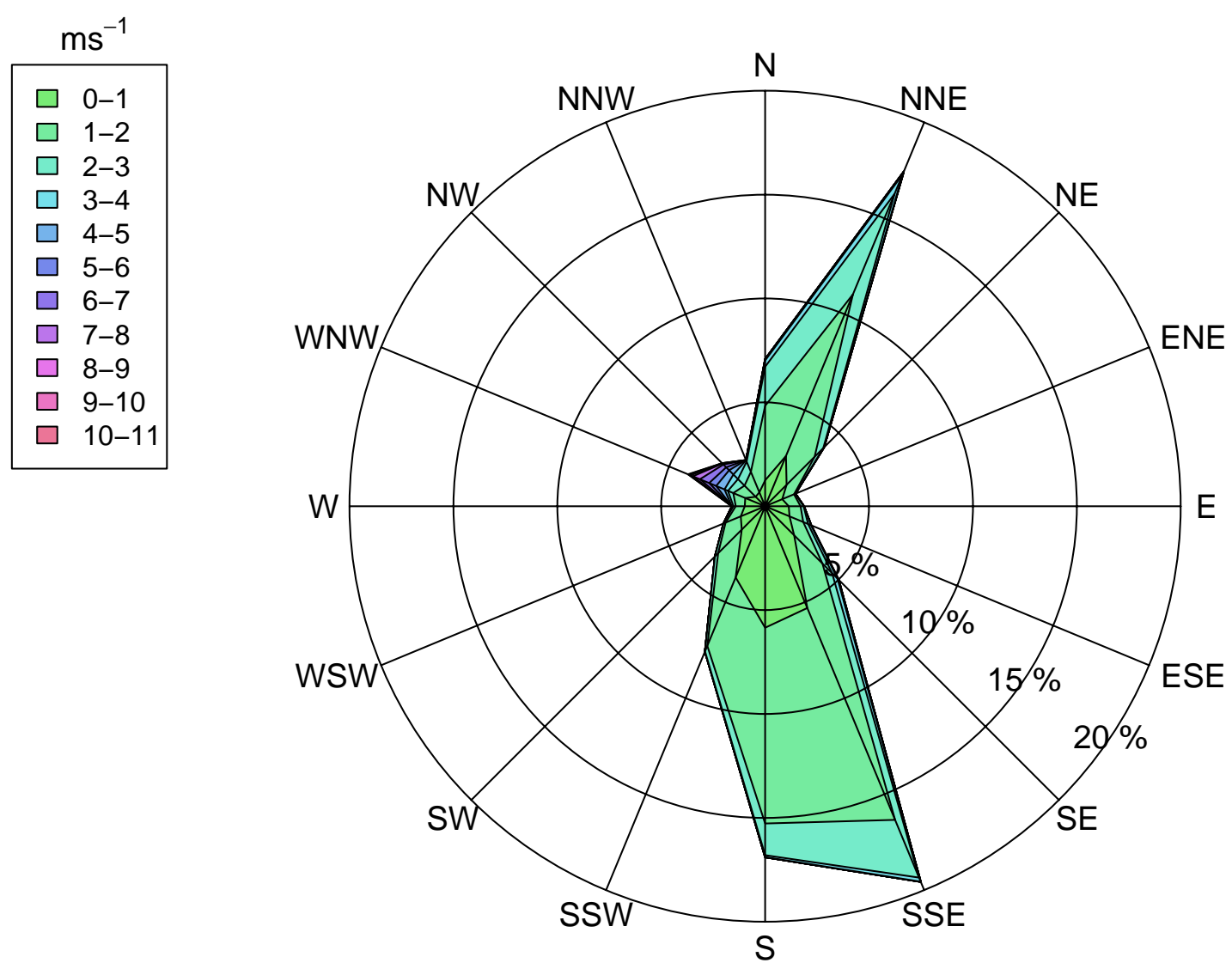

This article is protected by copyright. All rights reserved. 
Figure 3. Boxplots of the wind directions difference, $\Delta$ dir , between the $25-\mathrm{m}$ and the 5 -m levels. On each box, the central mark is the median, the edges of the box are the 25th and 75th percentiles. The whiskers length is 1.5 times the interquartile range. Black lines: low-wind cases; grey lines: windy cases; full grey dots: class-averaged difference $\overline{\Delta d i r}$.

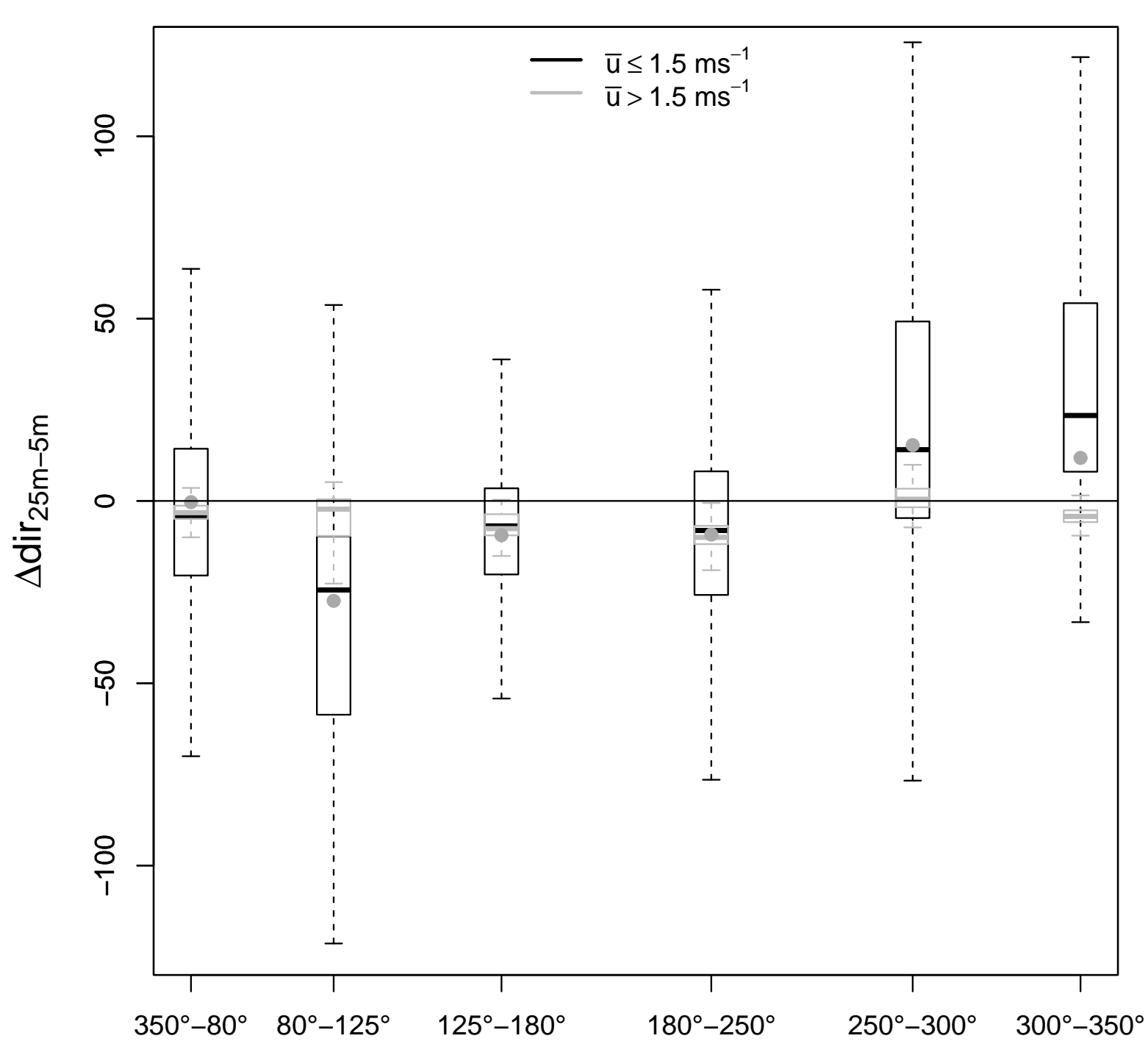

This article is protected by copyright. All rights reserved. 
Figure 4. Friction velocity at $5 \mathrm{~m}$ (left) and $25 \mathrm{~m}$ (right) as a function of the wind speed, for the Spring-Summer period (dots) and Autumn-Winter period (asterisks). The solid lines correspond to the best-fit curve for the two periods, Spring-Summer (slope $m=0.35$ ) and Autumn-Winter (slope $m=$ 0.26). The vertical dashed line indicates the $1.5 \mathrm{~m} \mathrm{~s}^{-1}$ low-wind value.

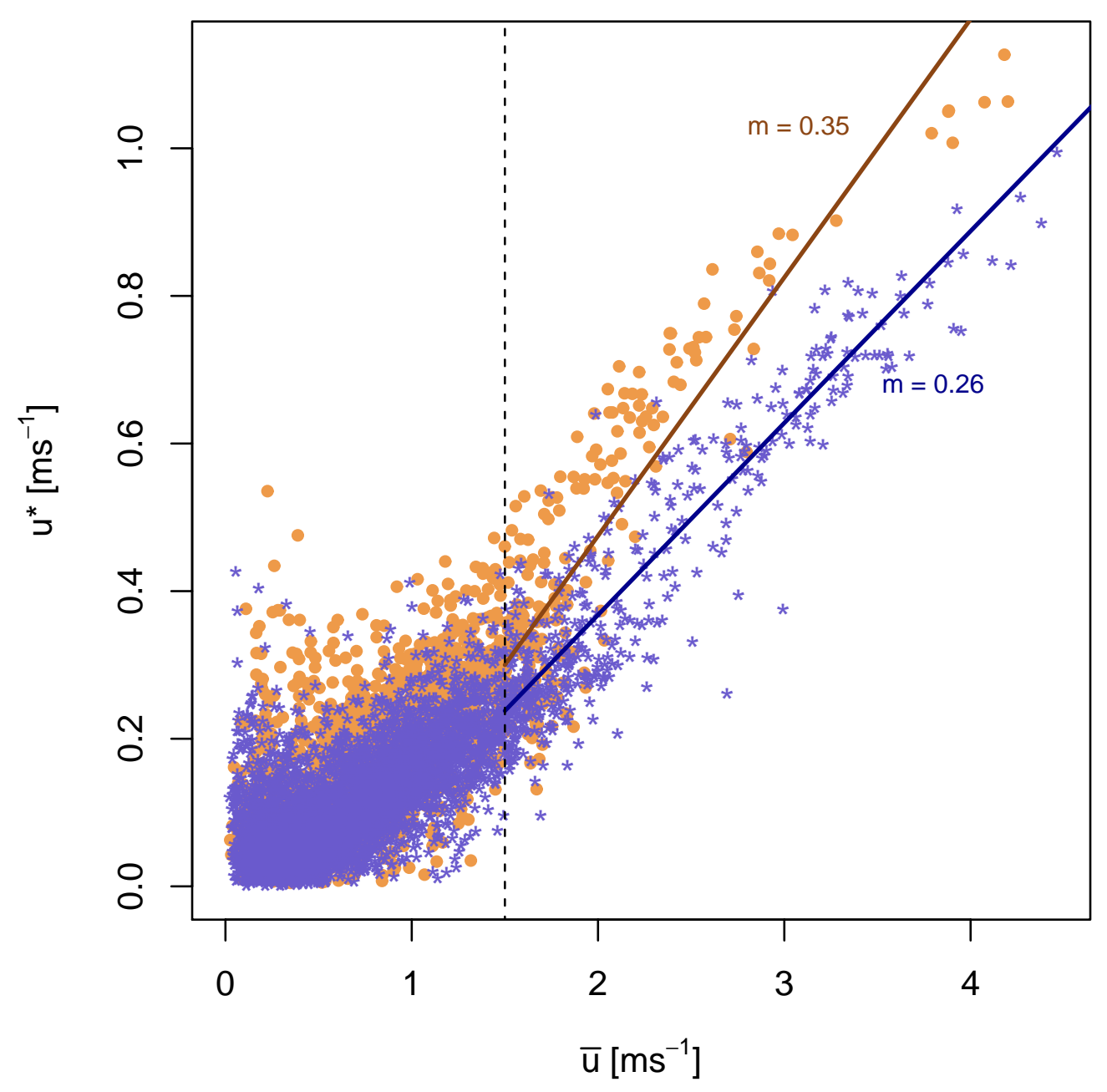

This article is protected by copyright. All rights reserved. 
Figure 5. Heat flux at $5 \mathrm{~m}$ (left) and $25 \mathrm{~m}$ (right) as a function of the wind speed for the Day hours (dots), Night hours (diamonds) and Transition hours (crosses). The horizontal dashed line indicates the zero values for the heat flux. The vertical dashed line indicates the $1.5 \mathrm{~ms}^{-1}$ low-wind value.

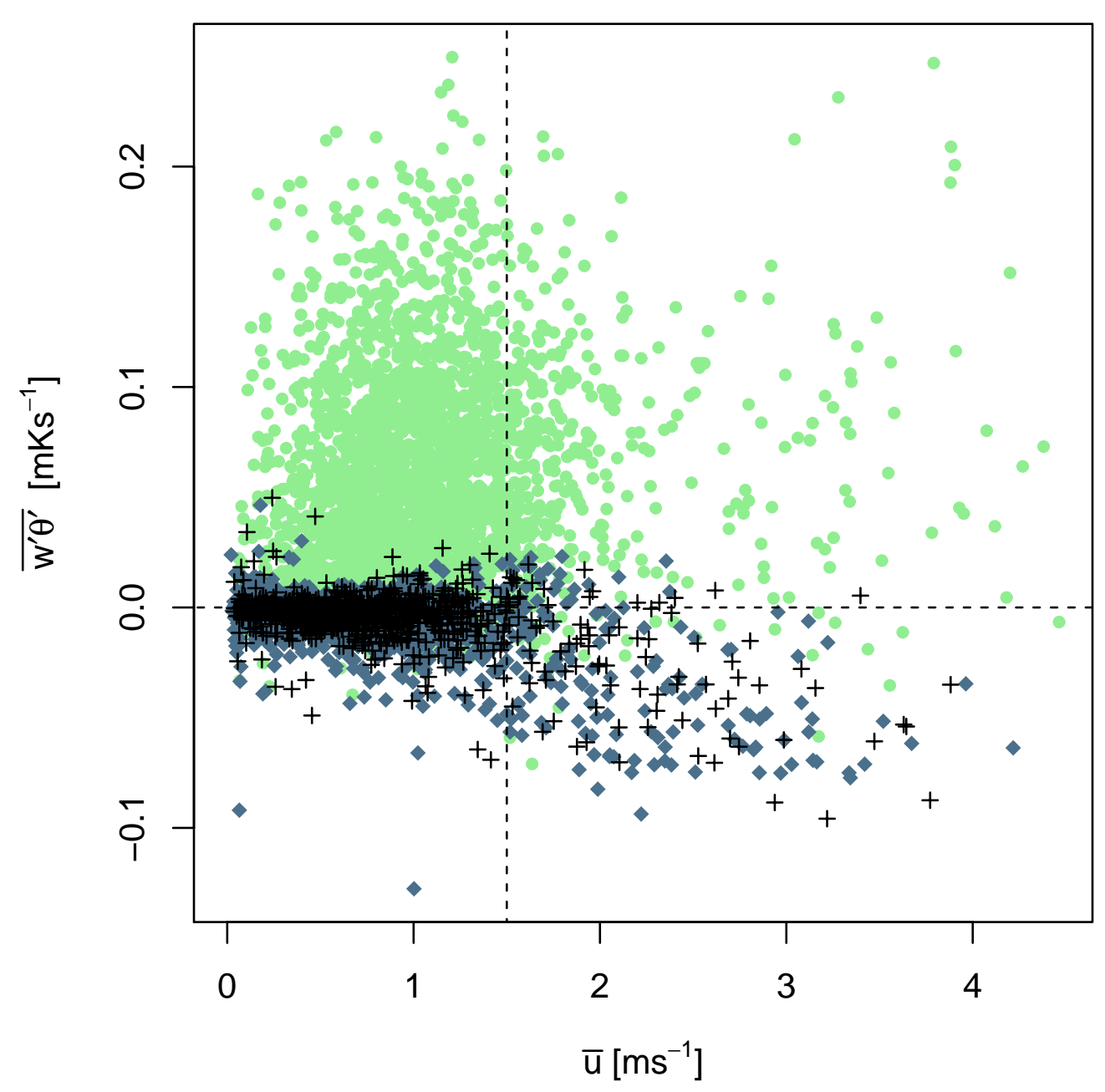

This article is protected by copyright. All rights reserved. 
Figure 6. Scatter diagrams between the friction velocities, grouped in wind-speed classes, as follows: six $0.2-\mathrm{ms}^{-1}$ classes for $0<\bar{u}_{* 5 m}<1.2 \mathrm{~ms}^{-1}$, one class respectively for $1.2<\bar{u}_{* 5 m}<1.5$, $1.5<\bar{u}_{* 5 m}<2,2<\bar{u}_{* 5 m}<3$ and $\bar{u}_{* 5 m}>3 \mathrm{~ms}^{-1}$. Left: comparison between the 5-m level (abscissa) and the 9-m one; right: comparison between the 9-m level and the $25-\mathrm{m}$ one. The $m=1.38$ (left) and $m=1.23$ (right) are the slopes of the scatter-points line (solid line), compared to the perfectagreement line (dashed line).
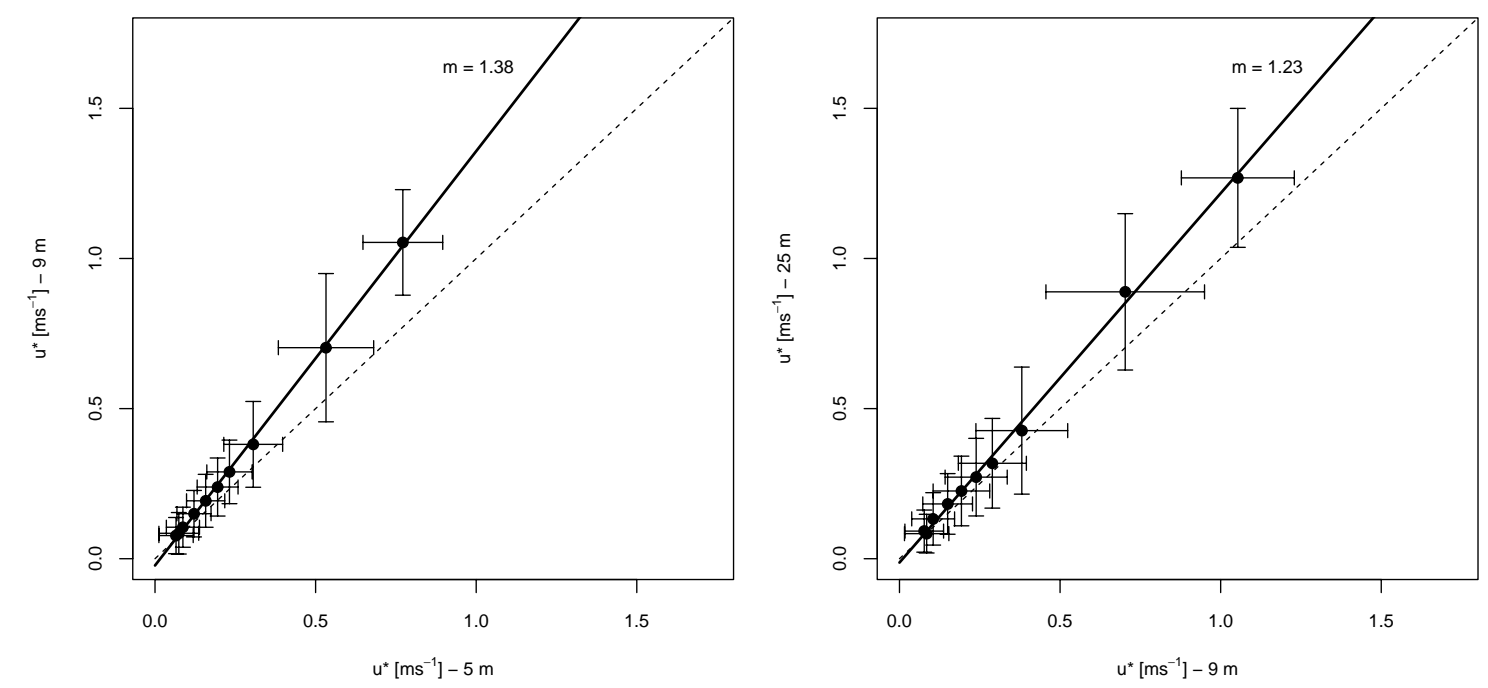

This article is protected by copyright. All rights reserved. 
Figure 7. Wind velocity standard deviations normalized over the friction velocity, averaged over stability classes, at the three levels: $5 \mathrm{~m}$ (left), $9 \mathrm{~m}$ (centre) and $25 \mathrm{~m}$ (right). Observations: dots; observation standard deviations: bars. Best-fit curves: black solid line. Curve with Moraes et al. (2005) coefficients: grey solid line.
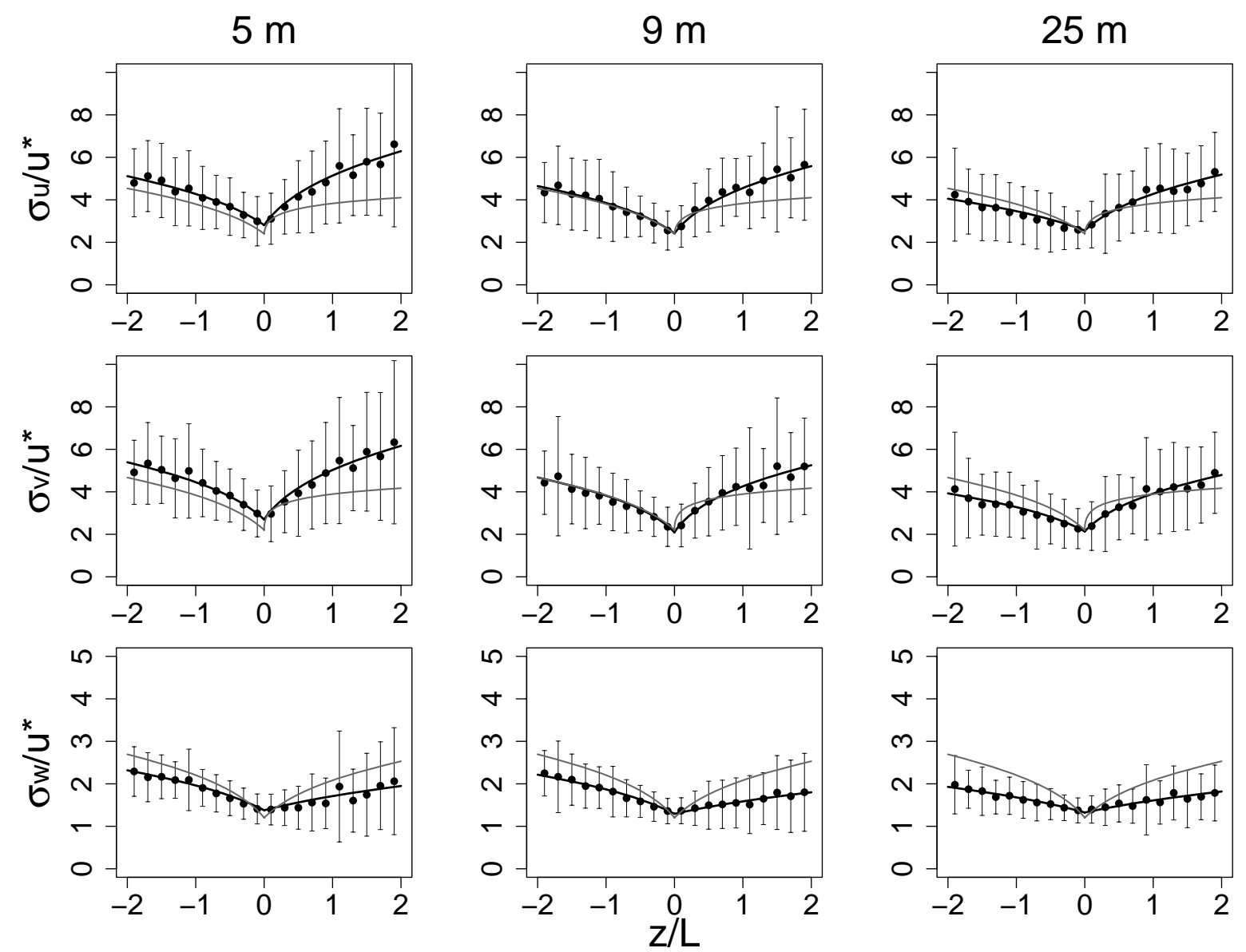
Figure 8. Wind velocity standard deviations normalized over the friction velocity, averaged over stability classes, at the three levels: $5 \mathrm{~m}$ (left), $9 \mathrm{~m}$ (centre) and $25 \mathrm{~m}$ (right). Best-fit curve: solid line; Hanna (1982) parameterization: dots; Degrazia et al. (2000) parameterization: diamonds.
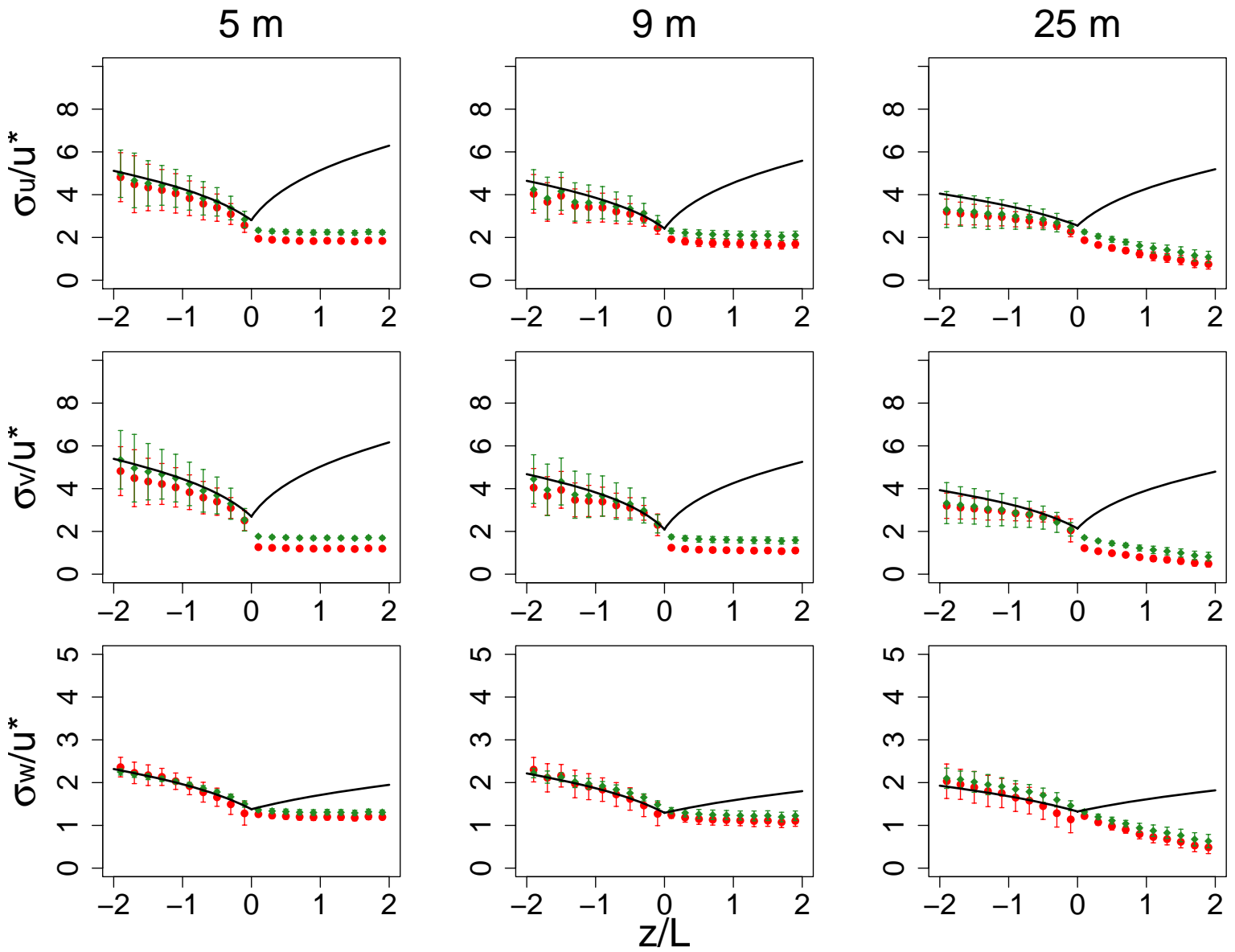

This article is protected by copyright. All rights reserved. 
Table I. Percentages of reference values for the wind speed and stability conditions at the three levels.

\begin{tabular}{|c|c|c|c|}
\hline level & $5 \mathrm{~m}$ & $9 \mathrm{~m}$ & $25 \mathrm{~m}$ \\
\hline \multicolumn{4}{|l|}{ Wind speed } \\
\hline $\bar{u}<1 \mathrm{~ms}^{-1}$ & $70 \%$ & $60 \%$ & $30 \%$ \\
\hline $\bar{u}<1.5 \mathrm{~ms}^{-1}$ & $92 \%$ & $86 \%$ & $60 \%$ \\
\hline $\bar{u}>3 \mathrm{~ms}^{-1}$ & $1 \%$ & $2 \%$ & $6 \%$ \\
\hline $\operatorname{maximum} \bar{u}$ & $4.5 \mathrm{~ms}^{-1}$ & $6.4 \mathrm{~ms}^{-1}$ & $10.9 \mathrm{~ms}^{-1}$ \\
\hline \multicolumn{4}{|l|}{ Stability conditions } \\
\hline Unstable cases $-500<L<0 \mathrm{~m}$ & $49 \%$ & $51 \%$ & $61 \%$ \\
\hline Stable cases $0<L<500 \mathrm{~m}$ & $48 \%$ & $42 \%$ & $31 \%$ \\
\hline Neutral cases $|L|>500 \mathrm{~m}$ & $3 \%$ & $7 \%$ & $8 \%$ \\
\hline "Day" hours in stable subset & $9 \%$ & $8 \%$ & $9 \%$ \\
\hline "Night" hours in unstable subset & $19 \%$ & $17 \%$ & $25 \%$ \\
\hline Stable cases for $\bar{u}<1.5 \mathrm{~ms}^{-1}$ & $49 \%$ & $49 \%$ & $35 \%$ \\
\hline Unstable cases for $\bar{u}<1.5 \mathrm{~ms}^{-1}$ & $49 \%$ & $47 \%$ & $62 \%$ \\
\hline Neutral cases for $\bar{u}<1.5 \mathrm{~ms}^{-1}$ & $2 \%$ & $4 \%$ & $3 \%$ \\
\hline
\end{tabular}

This article is protected by copyright. All rights reserved. 
Table II. Morphological and roughness parameters calculated for all directions and with the different methods, morphometric (MM1 and MM2) or anemometric (AM).

\begin{tabular}{c|c|c|c|c|c|c||c|c}
\hline Method & \multicolumn{3}{|c|}{ MM1 } & \multicolumn{3}{c||}{ MM2 } & \multicolumn{3}{c}{ AM } \\
\hline \hline$z_{H}(\mathrm{~m})$ & \multicolumn{2}{|c|}{7.0} & \multicolumn{2}{|c||}{4.7} & - & - \\
\hline$\lambda_{p}$ & \multicolumn{2}{|c|}{0.18} & \multicolumn{2}{|c|}{0.14} & - & - \\
\hline \hline & $R t$ & $K u$ & $C o$ & $R t$ & $K u$ & $C o$ & $A l l \bar{u}$ & $\bar{u}>3 \mathrm{~ms}^{-1}$ \\
\hline$z_{d}(\mathrm{~m})$ & 3.5 & 4.2 & 1.5 & 2.4 & 2.7 & 0.7 & 0.7 & 2.8 \\
$z_{0}(\mathrm{~m})$ & 0.7 & 1.0 & 0.8 & 0.5 & 0.5 & 0.3 & 0.3 & 0.5 \\
\hline
\end{tabular}

This article is protected by copyright. All rights reserved. 
Table III. Morphological and roughness parameters in the six angular sectors: an example with formulation $\mathrm{Ku}$ is given for the roughness parameters by methods MM1 and MM2.

\begin{tabular}{cccccccc}
\hline & Sectors & $350^{\circ}-80^{\circ}$ & $80^{\circ}-125^{\circ}$ & $125^{\circ}-180^{\circ}$ & $180^{\circ}-250^{\circ}$ & $250^{\circ}-300^{\circ}$ & $300^{\circ}-350^{\circ}$ \\
\hline$z_{H}$ & MM1 & 8.2 & 6.3 & 4.8 & 6.4 & 7.8 & 7.6 \\
& MM2 & 10.3 & 3.9 & 4.2 & 4.3 & 4.8 & 4.6 \\
\hline$\lambda_{p}$ & MM1 & 0.23 & 0.27 & 0.08 & 0.10 & 0.18 & 0.19 \\
& MM2 & 0.20 & 0.16 & 0.08 & 0.11 & 0.16 & 0.24 \\
\hline & MM1-Ku & 1.6 & 1.5 & 0.3 & 0.5 & 1.1 & 1.2 \\
$z_{0}$ & MM2-Ku & 1.7 & 0.5 & 0.3 & 0.3 & 0.6 & 0.9 \\
& AM & 0.5 & 0.3 & 0.3 & 0.3 & 0.5 & 0.6 \\
\hline & MM1-Ku & 4.1 & 3.2 & 2.4 & 3.2 & 3.9 & 3.8 \\
$z_{d}$ & MM2-Ku & 5.2 & 1.9 & 2.1 & 2.1 & 2.4 & 2.3 \\
& AM & 1.7 & 0.7 & 0.3 & 0.4 & 1.6 & 2.1 \\
\hline
\end{tabular}


Table IV. Vertical variability of the class-averaged observed friction velocity as a function of angular sector classes and as a function of stability classes.

\begin{tabular}{|c|c|c|c|c|}
\hline & & $\begin{array}{c}\text { Number of } \\
\text { data }\end{array}$ & $\begin{array}{c}\bar{u}_{* 25 m}-\bar{u}_{* 5 m} \\
\left(m s^{-1}\right)\end{array}$ & $\begin{array}{c}\frac{\bar{u}_{* 25 m}-\bar{u}_{* 5 m}}{\bar{u}_{* 5 m}} \\
(\%)\end{array}$ \\
\hline Angular sector & $\begin{array}{l}350^{\circ}-80^{\circ} \\
80^{\circ}-125^{\circ} \\
125^{\circ}-180^{\circ} \\
180^{\circ}-250^{\circ} \\
250^{\circ}-300^{\circ} \\
300^{\circ}-350^{\circ}\end{array}$ & $\begin{array}{l}1670 \\
277 \\
2126 \\
1133 \\
259 \\
333\end{array}$ & $\begin{array}{l}0.10 \\
0.06 \\
0.01 \\
0.04 \\
0.15 \\
0.16\end{array}$ & $\begin{array}{l}65 \\
47 \\
12 \\
35 \\
59 \\
60\end{array}$ \\
\hline $\begin{array}{c}\text { Stability-parameter } \\
\text { class }\end{array}$ & $\begin{array}{l}-1 \leq\left(\frac{z}{L}\right)_{25 m}<-0.5 \\
-0.5 \leq\left(\frac{z}{L}\right)_{25 m}<-0.05 \\
-0.05 \leq\left(\frac{z}{L}\right)_{25 m}<-0.01 \\
-0.01 \leq\left(\frac{z}{L}\right)_{25 m}<0.01 \\
0.01 \leq\left(\frac{z}{L}\right)_{25 m}<0.05 \\
0.05 \leq\left(\frac{z}{L}\right)_{25 m}<1\end{array}$ & $\begin{array}{l}602 \\
1095 \\
181 \\
116 \\
147 \\
954\end{array}$ & $\begin{array}{l}0.07 \\
0.11 \\
0.21 \\
0.26 \\
0.17 \\
0.07\end{array}$ & $\begin{array}{l}46 \\
63 \\
62 \\
66 \\
73 \\
79 \\
59\end{array}$ \\
\hline
\end{tabular}

This article is protected by copyright. All rights reserved. 
Table V. Empirical coefficients estimated from a best-fit (formulation expressed in eq. (3)) for the normalized wind-velocity standard deviations.

\begin{tabular}{|c|c|c|c|c|c|c|c|c|}
\hline \multirow{2}{*}{ Level } & \multicolumn{3}{|c|}{$A_{i}$} & \multirow{2}{*}{ Stratification } & \multicolumn{3}{|c|}{$B_{i}$} & \multirow{2}{*}{$\begin{array}{c}C_{i} \\
i=u, v, w\end{array}$} \\
\hline & $i=u$ & $i=v$ & $i=w$ & & $i=u$ & $i=v$ & $i=w$ & \\
\hline$\sigma_{5 m}$ & & & & unstable & -2.52 & -3.51 & -1.88 & \\
\hline$u_{* 5 m}$ & 2.81 & 2.69 & 1.38 & stable & 5.12 & 5.49 & 0.91 & 0.33 \\
\hline$\sigma_{9 m}$ & & & & unstable & -3.06 & -5.09 & -2.01 & \\
\hline$u_{* 9 m}$ & 2.41 & 2.09 & 1.29 & stable & 5.69 & 7.42 & 0.84 & 0.33 \\
\hline$\sigma_{25 m}$ & & & & unstable & -1.49 & -2.60 & -1.04 & \\
\hline$u_{* 25 m}$ & 2.50 & 2.14 & 1.32 & stable & 3.69 & 5.14 & 0.79 & 0.33 \\
\hline
\end{tabular}

This article is protected by copyright. All rights reserved. 
Table VI. Statistics of the wind velocity standard deviations for Hanna (1982) (here $H$ ) and Degrazia et al. (2000) (here $D$ ) parameterizations.

\begin{tabular}{|c|c|c|c|c|c|c|c|c|}
\hline Level & & $\begin{array}{c}\text { Observed } \\
\text { Mean }\left(\mathrm{m} \mathrm{s}^{-1}\right)\end{array}$ & & $\begin{array}{c}\text { Predicted } \\
\text { Mean }\left(\mathrm{m} \mathrm{s}^{-1}\right)\end{array}$ & CORR & RMSE & FB & FA2 \\
\hline \multirow{6}{*}{$5 \mathrm{~m}$} & \multirow{2}{*}{$\sigma_{u}$} & \multirow{2}{*}{0.54} & $H$ & 0.46 & 0.89 & 0.17 & 0.15 & 0.84 \\
\hline & & & $D$ & 0.52 & 0.91 & 0.16 & 0.04 & 0.90 \\
\hline & \multirow{2}{*}{$\sigma_{v}$} & \multirow{2}{*}{0.54} & $H$ & 0.41 & 0.84 & 0.22 & 0.26 & 0.68 \\
\hline & & & $D$ & 0.47 & 0.88 & 0.18 & 0.13 & 0.83 \\
\hline & \multirow{2}{*}{$\sigma_{w}$} & \multirow{2}{*}{0.26} & $H$ & 0.25 & 0.96 & 0.05 & 0.05 & 0.95 \\
\hline & & & $D$ & 0.27 & 0.96 & 0.05 & -0.01 & 0.96 \\
\hline \multirow{6}{*}{$9 \mathrm{~m}$} & \multirow{2}{*}{$\sigma_{u}$} & \multirow{2}{*}{0.60} & $H$ & 0.52 & 0.91 & 0.19 & 0.14 & 0.79 \\
\hline & & & $D$ & 0.59 & 0.92 & 0.20 & 0.02 & 0.84 \\
\hline & \multirow{2}{*}{$\sigma_{v}$} & \multirow{2}{*}{0.55} & $H$ & 0.47 & 0.84 & 0.22 & 0.17 & 0.73 \\
\hline & & & $D$ & 0.53 & 0.89 & 0.20 & 0.04 & 0.81 \\
\hline & \multirow{2}{*}{$\sigma_{w}$} & \multirow{2}{*}{0.31} & $H$ & 0.30 & 0.96 & 0.07 & 0.04 & 0.90 \\
\hline & & & $D$ & 0.32 & 0.97 & 0.07 & -0.03 & 0.94 \\
\hline \multirow{6}{*}{$25 \mathrm{~m}$} & \multirow{2}{*}{$\sigma_{u}$} & \multirow{2}{*}{0.68} & $H$ & 0.57 & 0.88 & 0.24 & 0.17 & 0.74 \\
\hline & & & $D$ & 0.62 & 0.90 & 0.25 & 0.09 & 0.75 \\
\hline & \multirow{2}{*}{$\sigma_{v}$} & \multirow{2}{*}{0.62} & $H$ & 0.52 & 0.81 & 0.26 & 0.17 & 0.71 \\
\hline & & & $D$ & 0.56 & 0.85 & 0.26 & 0.10 & 0.74 \\
\hline & \multirow{2}{*}{$\sigma_{w}$} & \multirow{2}{*}{0.38} & $H$ & 0.34 & 0.92 & 0.12 & 0.10 & 0.81 \\
\hline & & & $D$ & 0.38 & 0.95 & 0.11 & -0.01 & 0.89 \\
\hline
\end{tabular}

